\title{
Advances in the evaluation of anorectal function
}

Emma V. Carrington ${ }^{1}$, S. Mark Scott ${ }^{1}$, Adil Bharucha ${ }^{2}$, François Mion ${ }^{3}$, Jose M. Remes-Troche ${ }^{4}$, Allison Malcolm ${ }^{5}$, Henriette Heinrich ${ }^{1}$, Mark Fox ${ }^{6,7}$ and Satish S. Rao ; on behalf of the International Anorectal Physiology Working Group and the International Working Group for Disorders of Gastrointestinal Motility and Function

Abstract | Faecal incontinence and evacuation disorders are common, impair quality of life and incur substantial economic costs worldwide. As symptoms alone are poor predictors of underlying pathophysiology and aetiology, diagnostic tests of anorectal function could facilitate patient management in those cases that are refractory to conservative therapies. In the past decade, several major technological advances have improved our understanding of anorectal structure, coordination and sensorimotor function. This Consensus Statement provides the reader with an appraisal of the current indications, study performance characteristics, clinical utility, strengths and limitations of the most widely available tests of anorectal structure (ultrasonography and MRI) and function (anorectal manometry, neurophysiological investigations, rectal distension techniques and tests of evacuation, including defecography). Additionally, this article provides our consensus on the clinical relevance of these tests.

Evacuation of bowel contents is highly regulated and requires coordinated function of the colon, rectum and anus ${ }^{1}$. Dysfunction of this unit can lead to faecal incontinence and/or symptoms of an evacuation disorder and can have a devastating effect on quality of life ${ }^{2}$. In North America, between $7 \%$ and $18 \%$ of community-dwelling adults report faecal incontinence ${ }^{3,4}$, and $12-19 \%$ of the population report evacuation disorders ${ }^{5}$ with an age-adjusted and sex-adjusted incidence approximately threefold greater than that of Crohn's disease $e^{6}$. Because the underlying aetiology and pathophysiology of faecal incontinence and evacuation disorders are multifactorial, reliance on symptoms alone to guide therapy is inadequate ${ }^{7}$.

The primary approach to a patient presenting for the first time with faecal incontinence or constipation with difficult defecation should be to exclude serious underlying pathology (such as colorectal malignancy and IBD $)^{8}$. In patients with symptoms refractory to first-line therapies such as lifestyle modification and optimization of stool consistency, it is justifiable to proceed with evaluation of anorectal structure, motor and sensory function ${ }^{9,10}$. The selection of appropriate investigations is often guided by the clinical history and examination. Such an evaluation should focus on determining the duration, type and severity of the patient's symptoms as well as identification of risk factors for symptom onset ${ }^{11}$. Epidemiological studies have identified a number of such risk factors, including increasing age, elevated BMI and presence of diarrhoea ${ }^{12,13}$. In women, obstetric injury is particularly relevant ${ }^{14-16}$ owing to the risk of damage to the pelvic floor, anal sphincters and pudendal nerves during the second stage of labour ${ }^{17,18}$. In men, iatrogenic injury to the sphincter complex secondary to anal surgery is a factor in up to $59 \%$ presenting for assessment ${ }^{19}$, and coexistent benign perianal disease (such as haemorrhoids, fistula-in-ano and radiation proctitis) is also common $^{20}$. In all patients, particular attention should be paid towards symptoms of other anorectal complaints (for example, faecal incontinence in a patient presenting with constipation) as data increasingly suggest that both faecal incontinence and evacuation disorders commonly coexist $^{21}$. Also, anorectal evaluation begins with a carefully performed digital rectal examination that can reveal several abnormalities, including dyssynergia, weak anal sphincters, sphincter defects and faecal impaction ${ }^{15,22}$.

No single test can fully characterize the causes of faecal incontinence and/or evacuation disorders. Instead, several tests are used to assess anorectal structure, motor and sensory function (TABLE 1). Data on the usefulness of these tests are conflicting, and some studies suggest that clinical examination alone is an adequate method for 


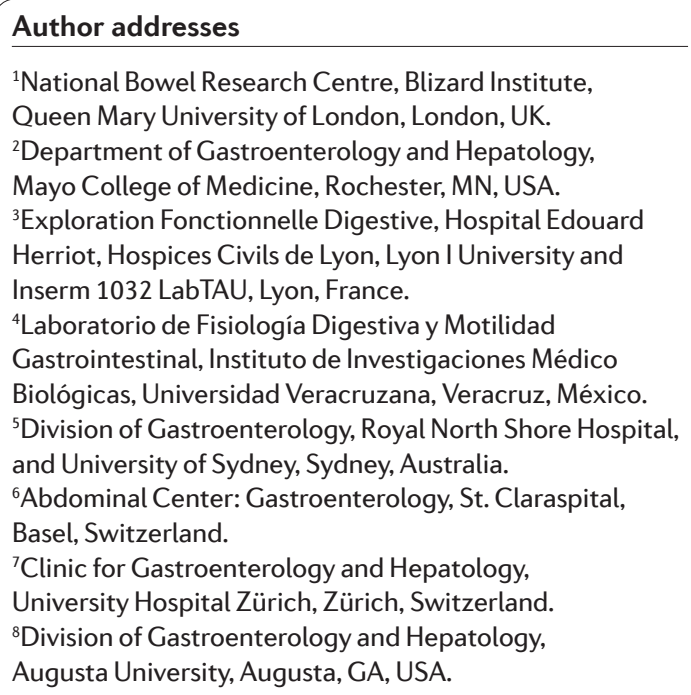

${ }^{1}$ National Bowel Research Centre, Blizard Institute, Queen Mary University of London, London, UK. 2Department of Gastroenterology and Hepatology, Mayo College of Medicine, Rochester, MN, USA. ${ }^{3}$ Exploration Fonctionnelle Digestive, Hospital Edouard Herriot, Hospices Civils de Lyon, Lyon I University and Inserm 1032 LabTAU, Lyon, France.

${ }^{4}$ Laboratorio de Fisiología Digestiva y Motilidad

Gastrointestinal, Instituto de Investigaciones Médico Biológicas, Universidad Veracruzana, Veracruz, México. ${ }^{5}$ Division of Gastroenterology, Royal North Shore Hospital, and University of Sydney, Sydney, Australia.

${ }^{6}$ Abdominal Center: Gastroenterology, St. Claraspital, Basel, Switzerland.

${ }^{7}$ Clinic for Gastroenterology and Hepatology, University Hospital Zürich, Zürich, Switzerland. ${ }^{8}$ Division of Gastroenterology and Hepatology, Augusta University, Augusta, GA, USA.

stratification of treatment ${ }^{22,23}$; however, there are data to suggest that quantification of function directly influences clinical decision-making ${ }^{24,25}$ and provides biomarkers that predict response to treatment ${ }^{26-28}$. However, despite several attempts at consensus ${ }^{29-31}$, there is widespread discordance in practices between institutions ${ }^{32}$. Such a disparity probably reflects factors such as access to technology, resource availability and local expertise; nevertheless, it is generally accepted that the clinical utility of tests improves when anorectal function is assessed in a structured and systematic manner ${ }^{33}$. Thus, the aim of this Consensus Statement is to provide the practising clinician with a background and framework regarding the indications, application and clinical interpretation of tests of anorectal function (BOX 1). Recommendations are based on a review of the literature and discussion by members of the International Anorectal Physiology Working Group (IAPWG) under the auspices of the International Working Group for Disorders of Gastrointestinal Motility and Function, a collective of clinicians and academics with particular interest and experience in the field of anorectal function testing.

\section{Methods}

The IAPWG steering committee (E.V.C., S.M.S., H.H., M.F. and S.S.R.) was appointed by the International Working Group for Disorders of Gastrointestinal Motility and Function. Under the guidance of the steering committee, the authors performed focused literature reviews in the following areas: anorectal manometry (ARM), anorectal neurophysiology, endoanal ultrasonography, pelvic floor ultrasonography, rectal sensory testing, balloon expulsion and defecography. Consensus was achieved through careful evaluation and discussion of available literature as well as expert agreement when recommendations lacked supporting evidence.

This Consensus Statement focuses on the tests that are widely available to the practising clinician and is divided into the following: tests of anal motor function ARM (conventional, high-resolution (HR-ARM) and 3D high-definition (3D-HR-ARM) and neurophysiology; tests of anal structure-endoanal or pelvic floor ultrasonography; tests of rectal sensory and motor functionsimple balloon distension and rectal barostat; and tests of evacuation-balloon expulsion and both barium and magnetic resonance (MR) defecography. Emerging technologies are also briefly addressed.

\section{Tests of anal motor function Anorectal manometry}

ARM is the most widely used technique for the detection of abnormalities of sphincter function and/or rectoanal coordination $^{15,29,31}$. This investigation consists of a series of pressure measurements that assess the following: involuntary function of the anal canal during rest; voluntary function during squeeze; reflex rectoanal coordination during rectal distension; and rectoanal coordination during simulated defecation ('push') , $29^{2}$.

Manometric equipment can record pressure data from single points in the anal canal (termed 'conventional anal manometry') or can record and display detailed information simultaneously from the whole anal canal and distal rectum (high-resolution manometry $)^{32,34}$. Although conventional anal manometry using a water-perfused system remains in clinical practice, studies suggest increased usage of the more detailed high-resolution solid-state methodology, probably in part due to the ability of this technique to more accurately characterize sphincteric function ${ }^{32}$.

Within the paradigm of high-resolution manometry, two technologies exist. HR-ARM records luminal pressures circumferentially from sensors mounted on a flexible catheter with data presented either topographically in colour plots or as an average circumferential pressure at different longitudinal levels of the anorectum $^{34}$. Conversely, 3D-HR-ARM records point pressures longitudinally and radially from sensors mounted on a rigid probe with morphology represented in both 2 and 3 dimensions ${ }^{34}$.

Study indications. ARM is typically indicated for the assessment of faecal incontinence and constipation, especially if characterized by symptoms of disordered evacuation. Relative indications for ARM include assessment of functional anorectal pain, preoperative assessment of anorectal function and assessment of anorectal function in patients after obstetric injury to inform treatment decisions concerning future mode of delivery $y^{7,29}$.

Study performance. Although not expected to be fully diagnostic, a digital rectal examination should be performed before intubation to provide an overview of anorectal and pelvic floor structure and function to exclude faecal loading, stricture, bleeding and pain. Checking a patient's understanding of instructions such as 'squeeze' and 'push' is also helpful. Studies are typically performed in the left lateral position, and any lubricant to aid probe placement should be non-anaesthetising. The probe is then positioned ensuring that the sensors span the distal rectum to beyond the anal verge. Both conventional and high-resolution techniques can use either waterperfused or solid-state technology for data collection, 
and detailed description of hardware and software setup and catheter design is described elsewhere ${ }^{35}$.

A standardized protocol for ARM would improve utility of the procedure, peer acceptance, translation and dissemination of results. The protocol recommended by the IAPWG is shown in FIG. 1. This protocol consists of the following standardized measurements: rest — basal anal pressures at rest over $60 \mathrm{~s}$; squeeze - anal pressure during voluntary effort; long squeeze - anal pressure during sustained voluntary effort; cough - anorectal pressure changes during cough (that is, reflex increase in rectal and anal sphincter pressures during abrupt change in intraabdominal pressure); push - anorectal pressure changes during simulated defecation; rectoanal inhibitory reflex (RAIR) - reflex anal response to rectal distension; and rectal sensation - assessment of rectal sensitivity to distension, typically performed as part of an ARM protocol (discussed in detail later).

Normal reference values for many of these variables have been described in three studies using HR-ARM ${ }^{36-38}$ and five using 3D-HR-ARM (three adult populations ${ }^{39-41}$,

Table 1 | Clinical utility of investigations of anorectal physiological function

\begin{tabular}{|c|c|c|}
\hline Function & Investigation & Clinical utility \\
\hline \multicolumn{3}{|l|}{ Anus } \\
\hline \multirow[t]{5}{*}{ Motor } & Anorectal manometry (conventional) & ++++ \\
\hline & Anorectal manometry (high resolution) & ++++ \\
\hline & Anorectal manometry (3D) & +++ \\
\hline & Electromyography & +++ \\
\hline & Pudendal nerve terminal motor latencies & + \\
\hline \multirow[t]{5}{*}{ Structure } & Endoanal ultrasonography & ++++ \\
\hline & Transperineal ultrasonography & +++ \\
\hline & Endoanal or pelvic MRI & +++ \\
\hline & MRI muscle fibre tracking & + \\
\hline & Electrostimulation & + \\
\hline \multirow[t]{2}{*}{ Sensory } & Light-touch stimulation & + \\
\hline & Anal evoked potentials & ++ \\
\hline \multicolumn{3}{|l|}{ Rectum } \\
\hline \multirow[t]{3}{*}{ Sensory } & Balloon distension & ++++ \\
\hline & Rectal barostat & +++ \\
\hline & Rectal evoked potentials & ++ \\
\hline \multirow[t]{3}{*}{ Motor } & Distal colonic manometry & ++ \\
\hline & Rectal barostat & +++ \\
\hline & Rectal motor evoked potentials & + \\
\hline \multicolumn{3}{|c|}{ Anorectal unit } \\
\hline \multirow[t]{2}{*}{ Motor } & $\begin{array}{l}\text { Anorectal manometry (conventional, high resolution } \\
\text { or 3D) }\end{array}$ & ++++ \\
\hline & Balloon expulsion & ++++ \\
\hline \multirow{3}{*}{$\begin{array}{l}\text { Motor, } \\
\text { sensory and } \\
\text { structure }\end{array}$} & Barium defecography & ++++ \\
\hline & Magnetic resonance defecography & +++ \\
\hline & Functional lumen imaging probe & + \\
\hline
\end{tabular}

+ , limited clinical utility or of research interest only; ++, emerging technology with limited data of clinical utility; +++, recognized clinical utility but less commonly performed; ++++, good clinical utility and commonly performed. one paediatric population ${ }^{42}$ and one series of primigravid women (first pregnancy) ${ }^{43}$. A number of similar reference values exist for conventional manometry; however, many studies use historical setups and protocols no longer in current use.

Clinical utility. A number of contemporary and historical studies have demonstrated differences in manometric findings between healthy volunteer and patient groups. Several clinically relevant features have been observed. Sphincter hypotonia (low anal resting pressure), although of low sensitivity, is associated with passive faecal incontinence $^{44-49}$ (FIG. 2a), whereas sphincter hypertonia (high anal resting pressure) can be a feature of anal fissure $e^{50-52}$ or constipation ${ }^{53}$. Sphincter hypocontractility (impaired ability to voluntarily contract the anal sphincter) is associated with faecal incontinence, particularly faecal urgency ${ }^{45,54}$, and poor propulsion (impaired rectal force during push), dyssynergia (paradoxical anal sphincter contraction during push) (FIG. 2b) and pelvic floor akinesia (failure of movement of the pelvic floor) ${ }^{55-57}$ have been noted in patients with evacuatory dysfunction. An absent rectoanal inhibitory reflex is classically seen in Hirschsprung disease ${ }^{58}$; however, abnormal responses can also be observed in patients with faecal incontinence ${ }^{59}$ and constipation ${ }^{60}$ and after anorectal surgery ${ }^{61}$.

In addition to these findings, 3D-HR-ARM has the ability to illustrate the normal asymmetry of pressures within the anal canal, with higher pressures in the posterior proximal and anterior distal regions of the sphincter. Deviation from this normal manometric anatomy can be detected on either $3 \mathrm{D}$ or $2 \mathrm{D}$ pressure plots at rest and/or squeeze and can be suggestive of pathology, although studies demonstrate only slight concordance with anal sphincter defects detected by endoanal ultrasonography ${ }^{62,63}$. Thus, pressure defects detected by 3D-HR-ARM should not be used as surrogate markers of anatomical anal sphincter defects without exercising caution.

Some evidence supports the hypothesis that pelvic floor abnormalities not previously identified by conventional ARM can be found with 3D-HR-ARM. Pilot studies suggest that this technique can measure pelvic floor descent ${ }^{64}$ and that results have a high positive predictive value (up to $100 \%, n=26$ ) for the presence of an intra-anal intussusception diagnosed by defecography ${ }^{65,66}$. These findings might be a useful indicator of the existence of pelvic floor disorders and help direct further investigation (such as defecography), especially in patients with symptoms of evacuation disorders.

Strengths and limitations. ARM is the best-established technology that provides a direct assessment of anal sphincter pressure and rectoanal coordination during simulated defecation. ARM is widely available, easy to perform and well accepted by patients. Interpretation of findings can, however, be difficult owing to the wide variability (and overlap) of manometric measurements in health and disease $\mathrm{e}^{48,67-70}$. Furthermore, some studies suggest that ARM offers little additional utility over digital rectal examination for planning patient 
management ${ }^{23}$. Additionally, owing to the striking variability in practices between institutions ${ }^{32}$, appropriate caution should be paid to using published reference ranges unless equipment design and test protocol mirror one's own. Study setup and patient position and the presence or absence of the perception of the desire to defecate, among others, can each have a major effect on absolute values reported (affecting both false-positive and false-negative rates) ${ }^{71-76}$.

\section{Anorectal neurophysiology}

Although less commonly used in clinical practice ${ }^{32}$ (owing to the adoption of less-invasive surrogate measures of sphincter function), anal electromyography and pudendal nerve terminal motor latencies (PNTMLs) remain important tools for assessment of anorectal neurophysiological function. The branches of the pudendal nerve, which course over the pelvic floor, are vulnerable to stretch injury (during the third trimester, second stage of labour and forceps-assisted vaginal delivery), which can lead to denervation of the external anal sphincter (EAS) and faecal incontinence ${ }^{77,78}$. Owing to the complex nature of symptom generation, such assessment is always performed in conjunction with other investigations (for example, ARM) to enable accurate understanding of the pathophysiological mechanisms in play.

Recording of pelvic floor electromyography (from both the EAS and levator ani muscles) enables mapping of the EAS to identify sphincter defects, determination of striated muscle function and assessment of denervation-reinnervation potentials (indicative of neural injury) ${ }^{79}$. PNTML measurement evaluates the neuromuscular integrity between the pudendal nerve and the anal sphincter ${ }^{7,31,79,80}$.

Study indications. Neurophysiological assessment is typically indicated for the investigation of symptoms of faecal incontinence thought to be secondary to neurological injury. Relative indications for neurophysiology include symptoms of anorectal pain and characterization of complex pelvic floor disorders, especially before anorectal surgery ${ }^{7}$.

\section{Box $1 \mid$ Key advances in evaluating anorectal function}

- Investigations of anorectal structure, function and sensation are indicated for the assessment of patients with symptoms suggestive of an evacuation disorder and/or faecal incontinence that are unresponsive to conservative therapy.

- No single investigation can fully assess anorectal function; for this reason, a range of techniques are generally used to characterize the pathophysiology and aetiology of symptoms.

- Anal endosonography and anorectal manometry (ARM) provide an assessment of sphincter structure and function in patients with symptoms of faecal incontinence; ARM with balloon expulsion and defecography identifies functional and/or structural pathology in patients with evacuation disorders.

- Investigations of anorectal sensation are a vital component of assessment in both faecal incontinence and evacuation disorders.

- Owing to the overlap of normal and abnormal values, the results of such functional investigations should be interpreted carefully, taking into context the clinical picture and the multifactorial aetiology of anorectal disorders.
Study performance. Studies of electromyographic activity are typically performed using a needle, skin or anal plug electrode. Disposable needle electrodes are inserted into the muscle under study, and parameters are recorded to describe insertional activity, spontaneous activity, motor unit action potential morphology and recruitment during voluntary or reflex activity. For PNTML, stimulation of the pudendal nerve using a disposable bipolar electrode generates a compound muscle action potential response of the EAS ${ }^{80}$. The PNTML is the time between stimulus artefact and the onset of the compound muscle action potential response.

Clinical utility. In the striated anal musculature of patients with faecal incontinence, motor unit action potential activity, fibre density and jitter (the stability of consecutive muscle fibre discharges, reflecting the stability of terminal motor axons and neuromuscular transmission) through recording of electromyography activity have all been shown to be altered in comparison with controls ${ }^{79,81-83}$. For PNTML, abnormal results (prolonged latencies) are used as a surrogate marker of pudendal neuropathy and indicate either demyelination or damage to a number of fast-firing fibres ${ }^{84}$.

Strengths and limitations. Electromyography findings correlate well with sphincter pressures ${ }^{85}$ (for example, electromyographic recruitment is seen simultaneously with increased anal pressures during squeeze). Intraluminal electrodes are believed to be more accurate because they are closer to the EAS muscle and are less likely to pick up artefact from gluteal or other muscles ${ }^{86}$. Currently, the most frequent application of electromyography is as a biofeedback signal for pelvic floor retraining of EAS function in patients with faecal incontinence or constipation ${ }^{87-89}$, and it can be especially useful to detect paradoxical contraction or impaired relaxation of the sphincter in those with evacuation disorders ${ }^{89}$.

The clinical utility of PNTML remains controversial, as there are several test limitations: it is operatordependent ${ }^{31}$; sensitivity and specificity are poor ${ }^{81,82}$; normal latencies can be recorded in a damaged nerve as long as some fast-conducting fibres remain ${ }^{90}$; and predictions of clinical outcomes after intervention are conflicting ${ }^{91}$. In addition, the upper limit of normal for latency is ill defined owing to substantial variability in healthy individuals ${ }^{7}$.

\section{Tests of anal structure}

\section{Endoanal and pelvic floor ultrasonography}

Endoanal ultrasonography ${ }^{92}$ is a simple and welltolerated technique that is widely used for detecting both internal anal sphincter (IAS) and EAS defects and has substantially increased our understanding of the pathogenesis of faecal incontinence. Total pelvic floor ultrasonography (integrating endoanal, transvaginal and transperineal ultrasonography) has been used to assess pelvic organ prolapse (that is, rectocele, enterocele, intussusception and cystocele $)^{93}$. Endoanal and/or pelvic MRI, although not widely available, are alternative imaging modalities available only in specialist centres ${ }^{93}$. 


\section{Study indications}

Endoanal or pelvic floor ultrasonography can be used for a number of indications: to evaluate the morphological integrity of the anal sphincters in patients with faecal incontinence, particularly when surgery is being considered, and to provide information on the pelvic viscera and pelvic floor movement in patients with symptoms of an evacuation disorder as a complementary investigation to ARM and defecography ${ }^{94}$. Moreover, these approaches can be used to assess obstetric anal sphincter injuries (OASIS) after childbirth to guide early repair and/or to inform planning of subsequent deliveries ${ }^{95,96}$. Other indications exist, particularly for the staging of rectoanal neoplasms (beyond the scope of this article) ${ }^{97}$. Transperineal ultrasonography has additional indications such as assessment of urinary incontinence, voiding difficulties and pelvic organ prolapse symptoms (again considered outside the scope of this article) ${ }^{93}$.

\section{Study performance}

Endoanal ultrasonography is performed in the lateral or prone position using a rigid endoprobe $(3-20 \mathrm{MHz})$, providing $360^{\circ}$ axial views of the sphincter complex ${ }^{92}$. Modern systems enable continuous capturing of images as the probe is withdrawn through the anal canal with post hoc multiplanar 3D image reconstruction and calculation of anal sphincter volumes.

During the performance of total pelvic floor ultrasonography, the patient is placed in the dorsal lithotomy position with the hips flexed and abducted. Transperineal ultrasonography uses a curved array probe $(5-9 \mathrm{MHz})$, whereas transvaginal scanning is performed using a linear array endoscopic probe $(12 \mathrm{MHz})$ to obtain dynamic $2 \mathrm{D}$ posterior and anterior mid-sagittal views. In addition to the detection of anal sphincter defects ${ }^{98}$, this technique enables evaluation of the dynamic interaction between the pelvic floor and viscera.

Anal anatomy is complex. On endoanal ultrasonography, two discrete rings of tissue are principally visualized: the inner hypoechoic IAS and the outer hyperechoic EAS, which is caudad to the puborectalis ${ }^{92}$. Several other structures, including the subepithelial tissues and conjoined longitudinal muscle, are also imaged. In contrast to 2D ultrasonography, 3D ultrasonography can also measure the length and volume of the EAS and might be better for distinguishing EAS defects from defects in surrounding structures (that is, the transverse perinei and puboanalis muscle) $)^{99}$. In addition to characterization of the sphincter complex, transperineal ultrasonography provides a dynamic evaluation of the interaction of the pelvic floor viscera and musculature, comprising assessment of the posterior, central and anterior compartments ${ }^{100}$.

\section{Clinical utility}

Endoanal ultrasonography is widely available and should be considered the cornerstone for anal imaging ${ }^{101}$ (FIG. 3). The IAS can be classified as normal or pathological, with the latter defined by several factors: sphincter discontinuity (defect) ${ }^{48}$ (FIG. 3b), atrophy (identified by diffuse thinning of the sphincter (thickness $\leq 1 \mathrm{~mm}$ ) ${ }^{102}$ ) (FIC. 3c) and/or degeneration ${ }^{103}$ or hypertrophy ${ }^{104,105}$. IAS defects

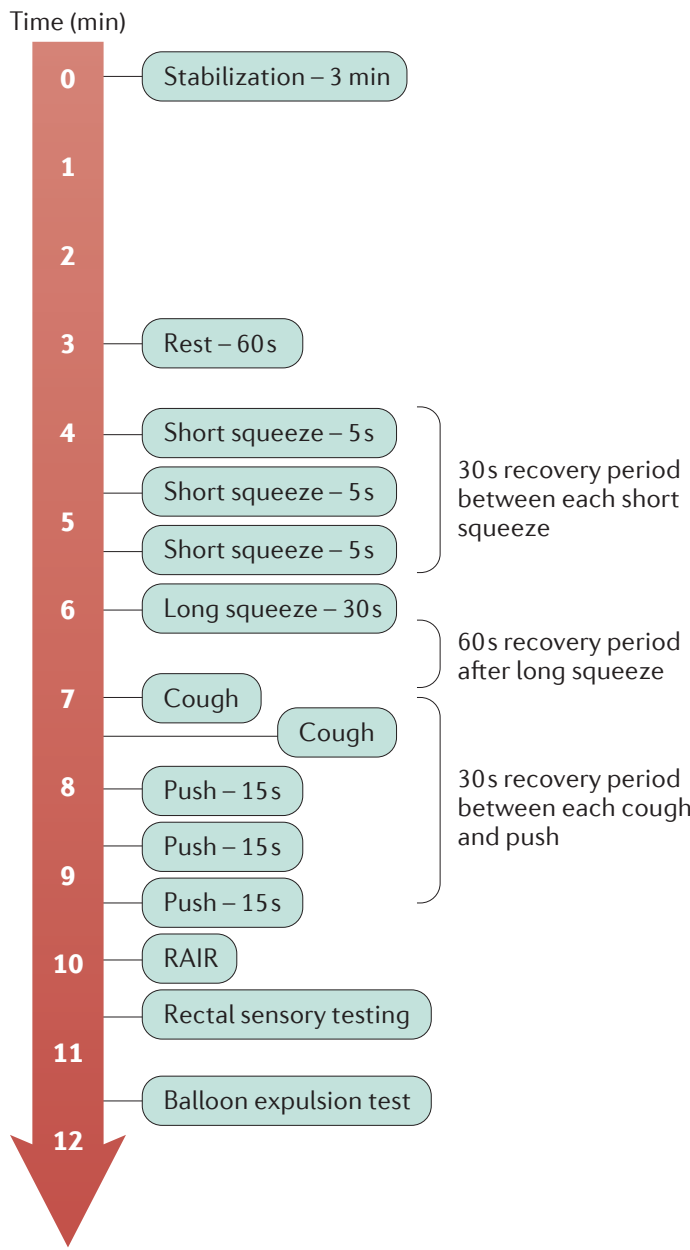

Figure 1 | Standardized protocol for high-resolution anorectal manometry. RAIR, rectoanal inhibitory reflex.

and/or atrophy are appreciated to be associated with symptoms of (particularly passive) faecal incontinence ${ }^{45,46,48}$. IAS hypertrophy is primarily seen in relation to rectal intussusception and/or prolapse ${ }^{105,106}$.

The EAS can be characterized as normal or pathological by sphincter discontinuity (defect) (FIG. 3d) or interruption of its fibrillar echotexture manifesting as focal thinning, scarring or atrophy ${ }^{92}$. All abnormalities can be described in cross section according to a clock face (for example, defect between 1 oclock and 3 oclock) and in the longitudinal plane. EAS disruption is a characteristic feature of OASIS ${ }^{107,108}$, is associated with anal hypocontractility ${ }^{109,110}$ and can be found in up to $68 \%$ of individuals presenting with symptoms of faecal incontinence $(n=200)^{111}$.

Total pelvic ultrasonography has the additional ability to enable classification of organ prolapse, describe structural and functional causes contributing to evacuation disorders ${ }^{93,100}$ and identify pubovisceral avulsion (abnormal insertion of the levator ani on the inferior pubic ramus, which is an important pathophysiological mechanism for pelvic organ prolapse and faecal incontinence $)^{112}$. Although not widely available, studies have also used a $4 \mathrm{D}$ approach to evaluate dynamic pelvic floor movement in real time ${ }^{113}$. 
a

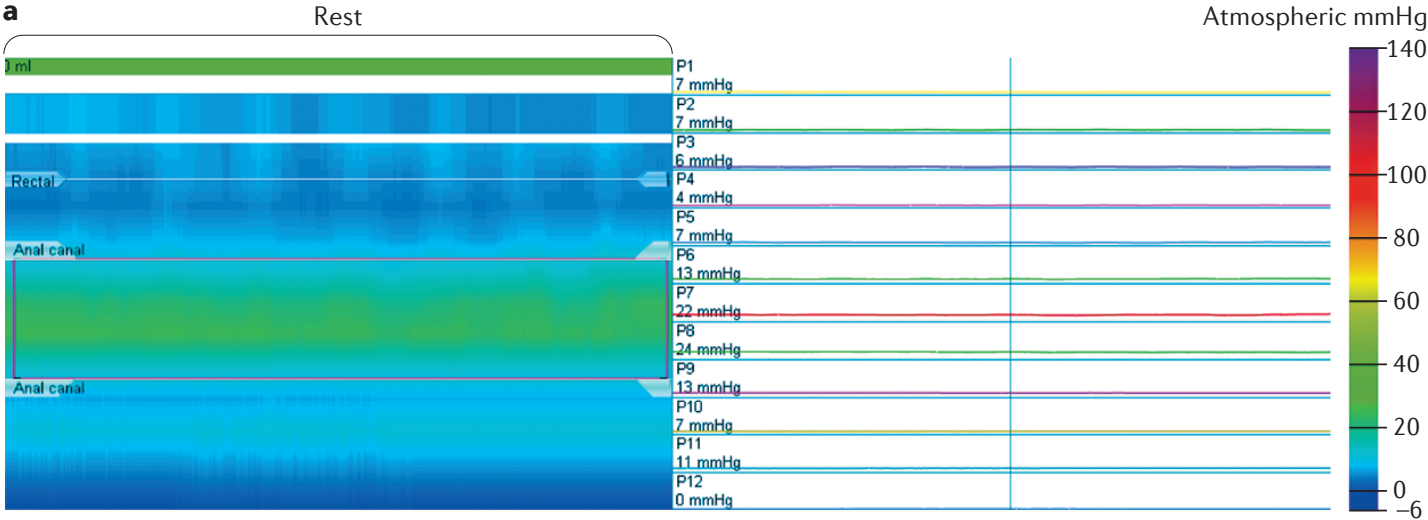

b

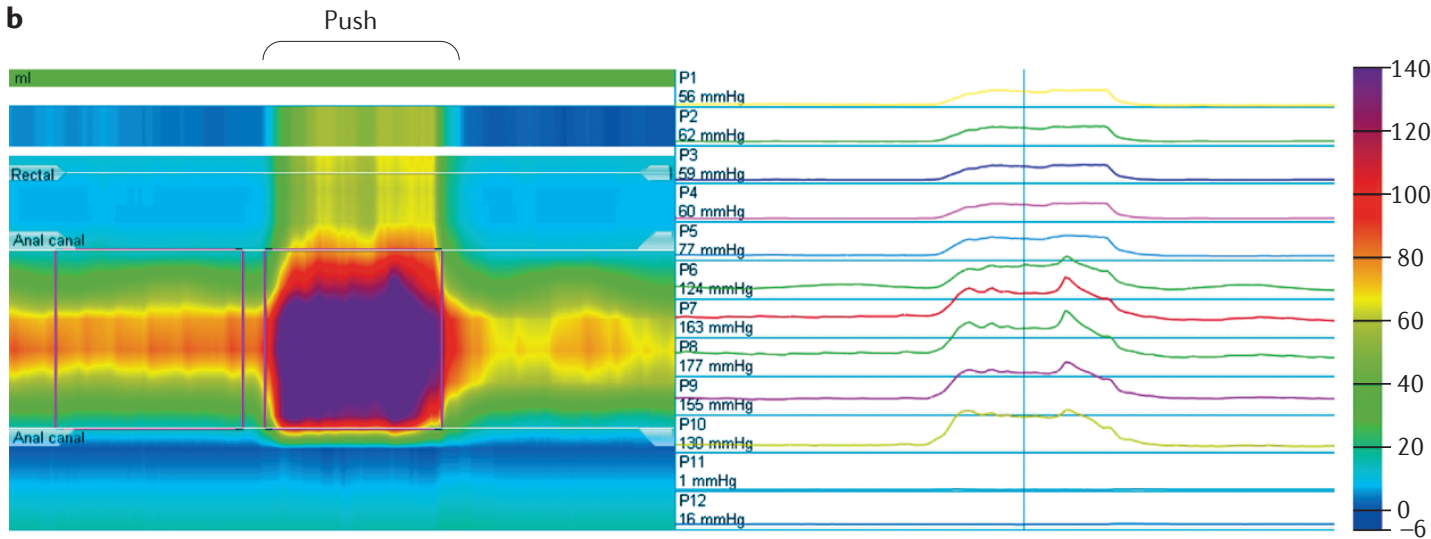

Figure 2 | Representative high-resolution anorectal manometry traces and resultant line traces to assess anorectal function. a | Sphincter hypotonia in a patient with faecal incontinence, visualized in the colour contour plot as a band of pale green ( $\sim 20-25 \mathrm{mmHg})$ set between normal blue $(\sim 5 \mathrm{mmHg})$ rectal (superiorly) and atmospheric (inferiorly) pressures. b | Dyssynergia (paradoxical anal sphincter contraction during push visualized in the colour contour plot as a band of purple $(\sim 150-175 \mathrm{mmHg})$ within the anal canal and a band of yellow $(\sim 50 \mathrm{mmHg})$ in a patient with evacuation disorder.

\section{Strengths and limitations}

Imaging of the anal sphincters can identify defects that are often clinically unrecognized and might be amenable to surgical repair. However, whereas abnormalities of anal structure are associated with anal hypotonia and hypocontractility ${ }^{48}$, it can be challenging to interpret the clinical relevance of this finding in isolation because $\sim 10 \%$ of women have postpartum (occult) sphincter defects without any symptoms ${ }^{99,114}$.

\section{Tests of anorectal sensory and motor function Simple balloon distension and rectal barostat}

Awareness of rectal filling is critical to normal bowel function ${ }^{7}$. Abnormal visceral sensitivity and/or biomechanical function (most commonly described by evaluation of rectal compliance) are often found in faecal incontinence and evacuation disorders ${ }^{7}$, providing the rationale for measurement of anorectal sensory and motor function via balloon distention and rectal barostat in clinical practice.

\section{Study indications}

Rectal sensory testing should be considered integral to physiological assessment of anorectal function. This testing is most commonly performed with simple balloon distension. Assessment with a rectal barostat, which is less widely available, should be considered in select patients with alterations of rectal sensation on 'standard' balloon distension and/or in whom there is a high index of suspicion of abnormal rectal compliance or capacity $7,115,116$. These tests enable the detection of heightened (hypersensitivity) or impaired and/or blunted (hyposensitivity) rectal sensation and/or abnormal rectal compliance or capacity (that is, 'stiff' or small (hypocompliant) or 'lax' or large (hypercompliant)).

\section{Study performance}

Rectal sensation is evaluated by assessing the perception of rectal distension ${ }^{7,15,116}$. For simple balloon distension, this test is performed by distending an elastic balloon, secured to a catheter placed within the rectum, with air (manually using a hand-held syringe or via a pump). Either ramp (continuous at $1-2 \mathrm{ml} / \mathrm{s}$ ) or intermittent (phasic or stepwise) distension paradigms can be used ${ }^{7}$. During balloon inflation, individuals are instructed to report perceived sensations (first sensation, desire to defecate, urgency and maximum toleration or pain). The distending volume (or, less frequently pressure) at each of these sensory thresholds is then recorded ${ }^{7}$.

Evaluation of both motor and sensory function is performed with a computerized barostat that enables distension at a specified and precise rate, thereby minimizing 
observer bias and measurement error ${ }^{7,115}$. An 'oversized', non-elastic bag is used that can be regarded as infinitely compliant (in that its own properties have no influence on internal pressure) (FIG. 4a). This method is preferable to measurements using balloons, which require correction to account for their intrinsic elasticity ${ }^{7,114}$. Patients are examined in a semi-prone or lateral position to reduce pelvic hydrostatic pressure. An initial 'conditioning' distention documents the minimal distending (that is, intra-abdominal) pressure and ensures that subsequent measurements are reproducible ${ }^{117}$ (FIG. 4b). Similar to the 'simple balloon' test described earlier, sensory thresholds are recorded during ramp or phasic distensions. Intraballoon (intrarectal) volumes and pressures are recorded concurrently, enabling rectal compliance to be calculated from the derived pressure-volume curve. Rectal capacity can also be measured (defined as barostat balloon volume at a prospectively defined, supraphysiological pressure; for example, $40 \mathrm{mmHg}^{118}$ ). Perceived sensations can alternatively be described using visual analogue scale scores (for example, urgency and pain)
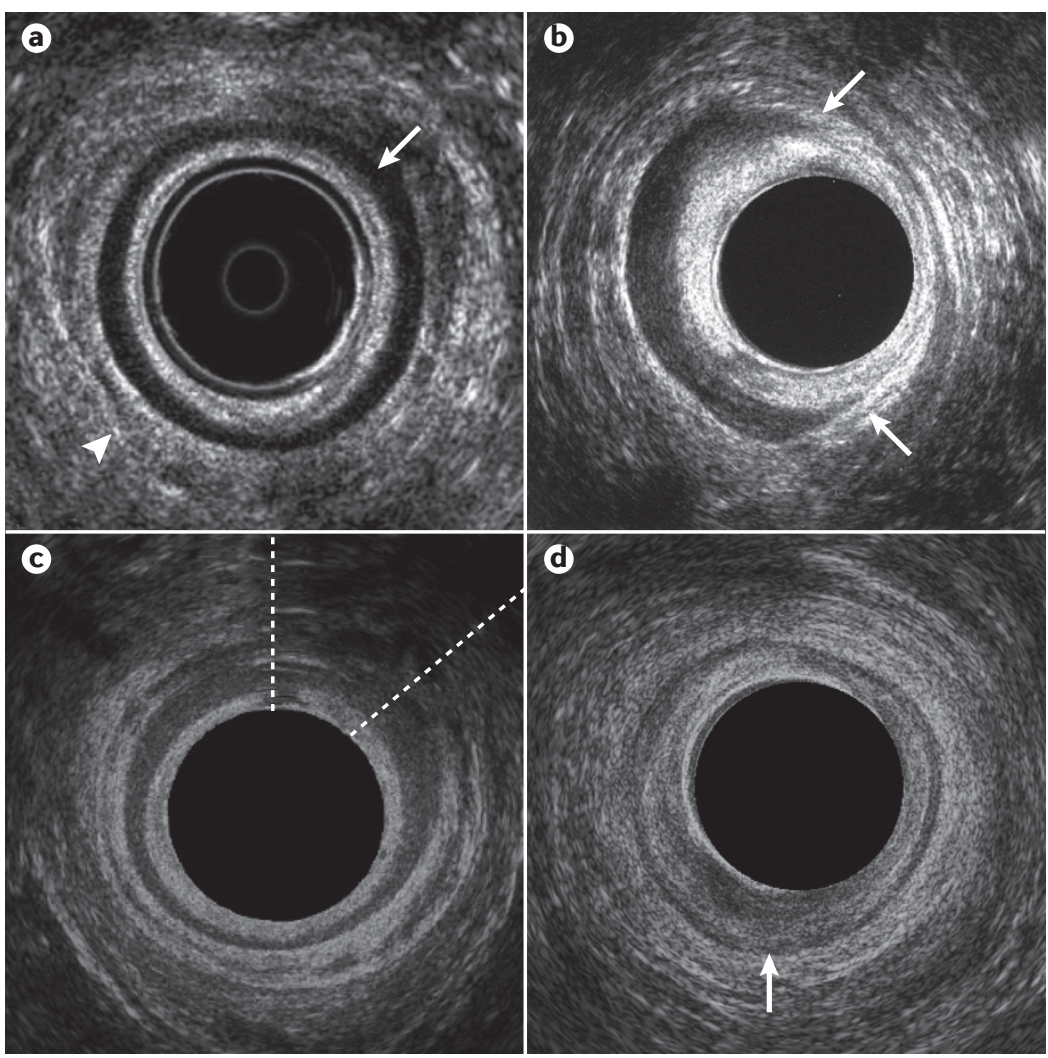

Figure 3 | Representative endoanal ultrasonography images. a |The mid-anal canal in a healthy volunteer, demonstrating an intact internal anal sphincter (IAS) (arrow) appearing hypoechoic and an intact external anal sphincter (EAS) (arrowhead) appearing hyperechoic. $\mathbf{b} \mid$ Mid-anal canal in a patient with faecal incontinence, demonstrating an IAS defect between the 1 o'clock and 5 o'clock positions (between the arrows). c | Mid-anal canal in a patient with faecal incontinence demonstrating an EAS defect, evident as an area of hypoechoic discontinuity between the 12 o'clock and 2 o'clock positions (extent of defect between dashed lines). $\mathbf{d}$ | Mid-anal canal in a patient with faecal incontinence demonstrating IAS atrophy (global thinning of the smooth muscle ring, which is of mixed echogenicity and is difficult to distinguish from surrounding structures; arrow). The EAS is intact. recorded on a $0-100 \mathrm{~mm}$ scale during distensions at set pressures (typically at $8,16,24$, and $32 \mathrm{mmHg}$ above operating pressure $)^{119}$.

\section{Clinical utility}

The thresholds for rectal sensation can be normal, reduced (hypersensitivity) or increased (hyposensitivity) in both faecal incontinence and chronic constipation $^{48,67,120}$. Demonstration of altered sensation can guide therapeutic measures aimed at normalizing sensory thresholds and relieving bowel symptoms.

Rectal hypersensitivity is a common finding in patients with symptoms of urgency and frequent defecation in diarrhoea-predominant IBS, ulcerative colitis and radiation proctitis. In IBS, this finding can be associated with increased symptom severity ${ }^{121}$. Rectal hypersensitivity is also a feature of faecal urgency and urge faecal incontinence ${ }^{122}$ and low anterior resection syndrome $e^{123}$. Such hypersensitivity can be related to reduced compliance, capacity or an exaggerated response to rectal distension ${ }^{124}$. Normalization of sensory thresholds in patients with hypersensitivity has been associated with positive clinical outcomes following the use of behavioural therapy, pharmacological agents and surgical interventions ${ }^{125-127}$; however, good outcomes are not necessarily associated with post-intervention changes in sensory parameters.

Rectal hyposensitivity (often found alongside an attenuated or absent call to stool ${ }^{128}$ ) is observed in $18-66 \%$ of patients with chronic constipation ${ }^{120}$, constipation-predominant IBS, faecal incontinence and evacuatory dysfunction secondary to spinal cord injury ${ }^{129}$. This finding can be 'primary' (due to direct impairment of afferent pathway function), 'secondary' (due to altered biomechanical properties; for example, megarectum) or both ${ }^{130}$. When hyposensitivity is present, the assumed mechanism is that stool is involuntarily expelled before the individual is alerted to the need to respond ${ }^{131}$. In such patients, sensory retraining has been shown to facilitate timely contraction of the external sphincter and improve continence ${ }^{132,133}$.

Demonstration of rectal hyposensitivity can indicate a severe clinical phenotype and predict a poor response to treatments such as biofeedback or bowel retraining ${ }^{134}$ and surgery with colectomy ${ }^{135}$. However, in those patients who do respond, normalization of impaired sensation is generally associated with an improvement in symptoms ${ }^{136,137}$, most notably during treatment with neuromodulation ${ }^{27}$.

\section{Strengths and limitations}

Several consensus statements and technical reviews acknowledge that evaluation of rectal sensory function has an accepted place in the clinical management of patients with anorectal disorders ${ }^{29,30,138,139}$. Nevertheless, methods for simple, elastic balloon distension are poorly standardized ${ }^{7}$. Although the use of a barostat overcomes these limitations, this technology is not widely available. However, development of a 'rapid' barostat ${ }^{38}$ could enable this approach to be performed in routine clinical practice (as a typical barostat protocol may take approximately 
1 hour to complete) $)^{7}$. For either technique, measurements can be affected by age, the rate and pattern of distention, patient position and biomechanical and structural properties of the rectum ${ }^{7,140,141}$; hence, it is essential for results to be interpreted in the context of appropriate normative values.

\section{Tests of evacuation \\ Balloon expulsion test}

Inability to expel solid stool from the rectum is a key feature of patients with constipation characterized by symptoms of an evacuation disorder. The balloon expulsion test (BET) is a direct method by which to assess this function.

Study indications and performance. Balloon expulsion is a simple, office-based test that is indicated as a first-line screening investigation for assessment of the ability to evacuate. With a patient lying in the left lateral position with hips and knees flexed, a lubricated, preferably non-latex balloon attached to a plastic catheter is inserted into the rectum and inflated with $50 \mathrm{ml}$ of warm water. The patient is then seated on a commode in privacy and asked to expel the balloon. The ability

a

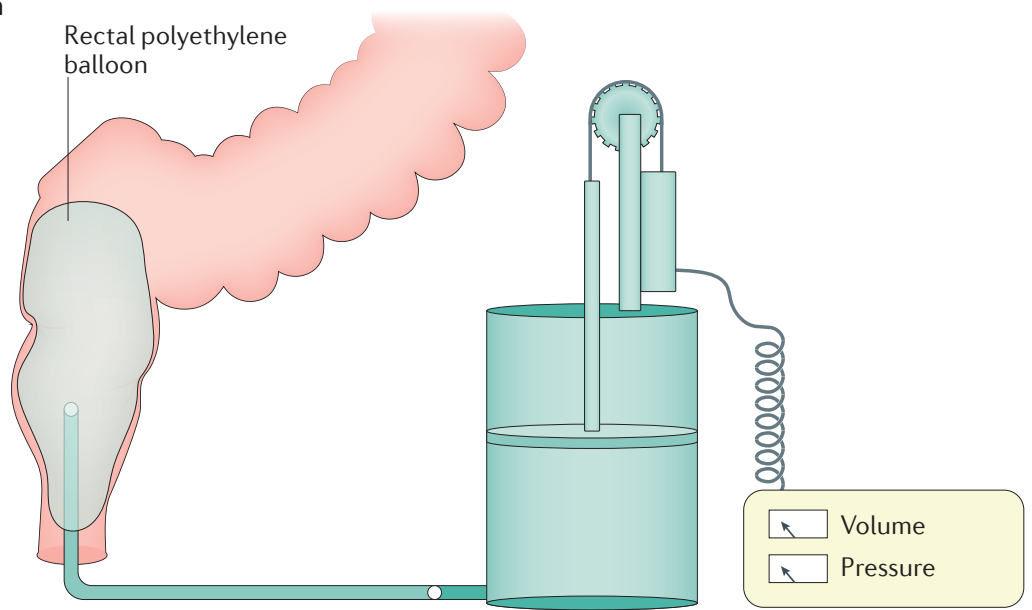

b

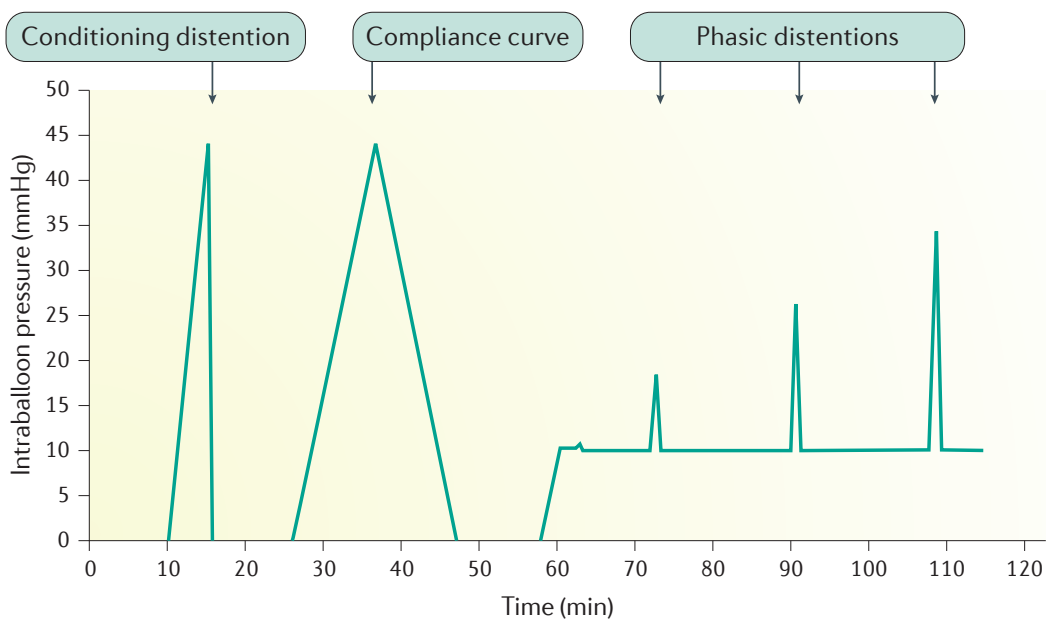

Figure 4 | Schematic of rectal barostat setup. a | Typical rectal barostat setup.

b|Barostat conditioning distension protocol. (or inability) to expel the balloon and the time taken for expulsion is recorded ${ }^{142}$. Although reported cut-offs for normality vary, the generally accepted limit for expulsion is between 1 and $3 \mathrm{~min}$. Expulsion times longer than this can indicate disordered evacuation ${ }^{142,143}$.

Clinical utility. Although often considered to be synonymous with dyssynergic defecation, it is pertinent to note that the sensitivity and specificity of this test is variable (ranging between $68-94 \%$ and $71-81 \%$, respectively $\left.{ }^{29,142,143}\right)$. Thus, BET in isolation is not sufficient to clearly diagnose an evacuation disorder ${ }^{144}$. Furthermore, agreement with other tests of evacuation is suboptimal (a prospective study of 100 patients with functional constipation published in 2016 showed only fair agreement between BET and defecography in diagnosing evacuation disorders and no agreement between BET and $\mathrm{ARM}^{145}$ ), and the BET provides no information about anatomical phenomena that might impair evacuation (for example, rectocele or occluding intussusception).

Nevertheless, studies do indicate that a positive result can predict response to biofeedback therapy with demonstration of a clinical response in up to $85 \%$ of patients $^{146-148}$, although this finding is not consistent across all studies ${ }^{149}$.

Strengths and limitations. Despite good reproducibility ${ }^{142}$, test setup and study performance are poorly stand$\operatorname{ardized}^{142,144}$. Demographic factors have an influence, with male participants having a shorter balloon expulsion time than women and expulsion time increasing with age ${ }^{150}$.

As a simple-to-perform, office-based screening test, balloon expulsion can be considered useful for the initial assessment of patients with symptoms of evacuation disorder; however, a firm diagnosis requires confirmation with other allied tests of evacuation.

\section{Defecography}

Barium (X-ray) defecography, or evacuation proctography, is an established clinical tool for the diagnosis of evacuation disorders ${ }^{151}$. Barium defecography evaluates rectal wall morphology, pelvic floor motion and evacuation in real time ${ }^{152}$. MR defecography enables imaging of all pelvic compartments ${ }^{153-155}$. In comparison with other tests of evacuatory function (for example, manometry, balloon expulsion and transperineal ultrasonography), defecography provides better overall evaluation of the defecatory process and structure and/or function of the anorectum ${ }^{7,115}$.

Study indications. Primary indications for both investigations (barium and MR defecography) are to identify structural or 'functional' obstructive features associated with impaired evacuation in patients with refractory symptoms of constipation consistent with an evacuation disorder; to identify impaired evacuation and/or pelvic organ prolapse in patients with faecal incontinence ${ }^{21,156}$; and to evaluate the effects of treatment, for example, after surgical repair of anorectal or pelvic floor pathology ${ }^{157,158}$. 

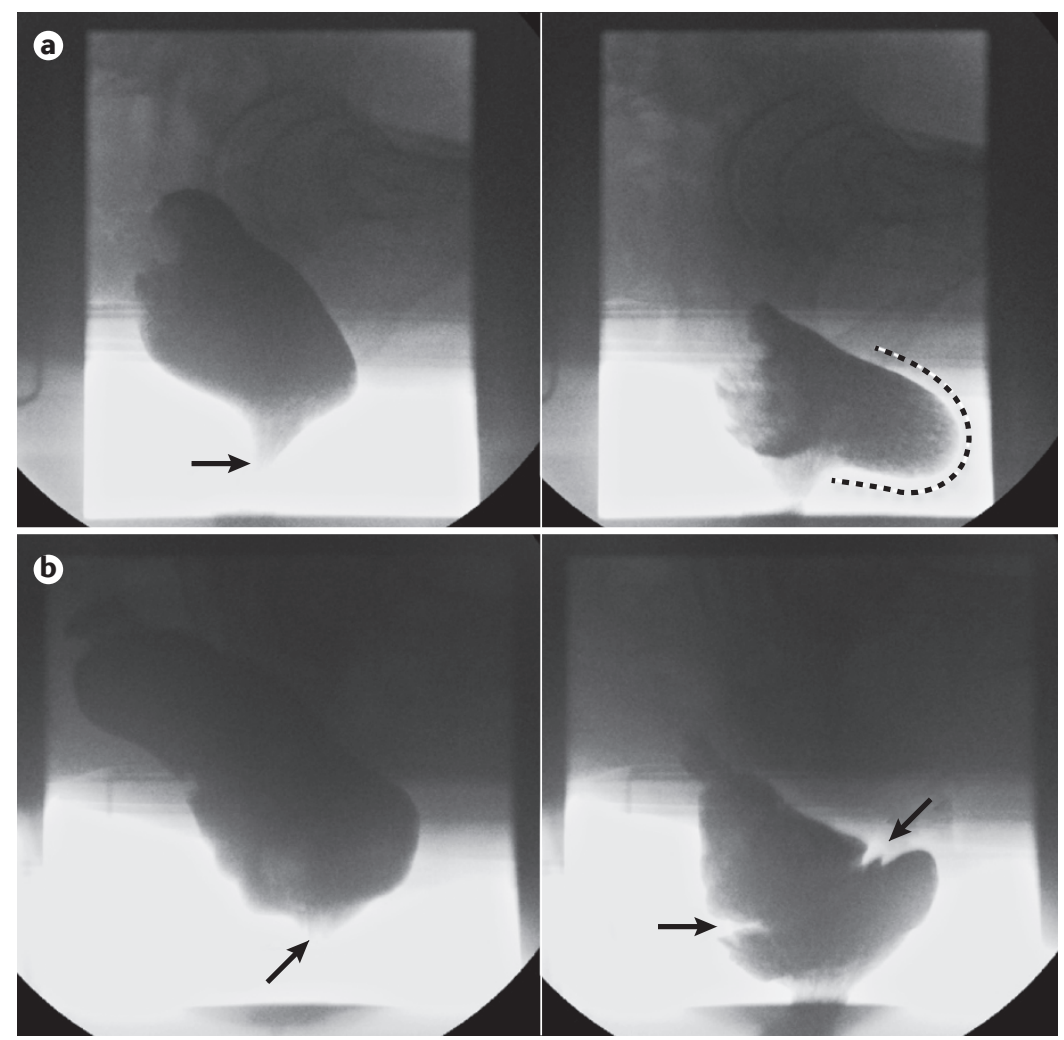

Figure 5 | Representative barium defecography images. a | A significant rectocele; the left panel shows a lateral view of the rectum at rest, opacified by barium neostool with the anal canal closed (arrow). The right panel clearly demonstrates a large retaining rectocele at end evacuation (extent of anterior bulging highlighted by dashed line). b | Obstructing full-thickness intussusception; the left panel shows a lateral view of the rectum at rest, with the anal canal closed (arrow). The right panel shows an image at mid-evacuation with clear invagination of the mid-rectum (between arrows) secondary to a full-thickness rectal intussusception; this is causing occlusion of the distal rectal lumen with retention of neostool proximal to this.

Study performance. Barium defecography involves fluoroscopic imaging of the anorectum during contraction of pelvic floor muscles and rectal evacuation (that is, simulated defecation) after barium paste, composed of barium sulfate, porridge oats and water, has been instilled into the rectum ${ }^{151,159}$. As rectal sensory function is critical to normal defecation ${ }^{159}$, introduction of a thick paste (approximating normal stool), to a volume individualized to a patient's desire to defecate ${ }^{160}$, might be preferable to a fixed volume of liquid barium. The patient is then seated upright on a radiolucent commode (in privacy behind a screen) during fluoroscopic screening and instructed to squeeze the anal sphincter and then expel rectal contents until evacuation is felt to be complete or the patient reports that they are unable to empty further. Rectal dimensions (length, diameter and capacity), anorectal angles, rectal wall morphological features, perineal descent and evacuatory efficacy (rate and percentage of contrast expelled) can be measured. However, the technique lacks standardization, and numerous modifications to the original method ${ }^{151}$ have been described, most notably opacification of bladder and/or vagina and/or small bowel (for example colpo-cysto-defecography), which enables concurrent visualization of cul-de-sac hernias (for example, enterocele) and other pelvic organ prolapses.

MR defecography can be performed either with the patient supine, within a closed-configuration magnet, or upright (sitting) within an open-configuration system ${ }^{154}$. However, limited availability of the latter means that the majority of studies are performed with the patient in a non-physiological supine position. The rectum is filled with a stool substitute (for example, mashed potatoes or ultrasonography gel) mixed with gadolinium if necessary.

Clinical utility. Barium defecography can identify impaired rectal evacuation and diagnose anatomical and 'functional' features that can contribute to symptoms of an evacuation disorder, such as rectocele (FIG. 5a), obstructing intussusception (FIG. 5b), rectal prolapse and megarectum, as well as dyssynergic defecation, levator ani and descending perineum syndrome ${ }^{152}$. With small bowel opacification, the effect of enterocele can be assessed. MR defecography additionally enables concurrent evaluation of bladder and vaginal vault descent and enables imaging in different orthogonal planes ${ }^{154}$.

Various grading systems exist for defining structural abnormalities and pelvic organ descent, both for barium $^{161-163}$ and MRI modalities ${ }^{153,164}$, and these can be used as a basis for guiding therapy, particularly in those abnormalities deemed amenable to surgical repair. However, anatomical findings such as a small rectocele or minor intussusception are frequently found in healthy individuals ${ }^{159,161}$, and failure to recognize such variants of normal can lead to overdiagnosis. A study using barium defecography has shown that an anterior rectocele is almost always present in asymptomatic female study participants ${ }^{159}$ and that only large $(>4 \mathrm{~cm})$ and/or retentive rectoceles (that might be smaller) should be regarded as clinically relevant. Intra-anal (as opposed to intrarectal) intussusception ${ }^{159}$ and enterocele ${ }^{165}$ are also appreciated to be pathological.

Limited comparative studies exist comparing modalities. Barium defecography better detects intussusceptions than MR defecography, either using supine ${ }^{166}$ or upright imaging ${ }^{167}$, and is more sensitive for identifying retentive rectoceles ${ }^{168,169}$. Upright MR defecography is superior to dynamic supine MRI in imaging intussusceptions; diagnostic utility is otherwise equivalent ${ }^{170}$.

Strengths and limitations. Of the available tests used to investigate patients with symptoms of an evacuation disorder, diagnostic agreement is imperfect ${ }^{145,171}$; however, only defecography evaluates evacuation and pelvic organ structure. For this reason, consensus documents recommend defecography either as a first-line $e^{138,172}$ or second-line ${ }^{10,139}$ test. MRI has several advantages over barium defecography in that it lacks exposure to ionizing radiation and provides excellent soft tissue resolution of all pelvic floor compartments and supporting structures, enabling assessment of coexisting cystocele and uterovaginal prolapse ${ }^{154}$.

There remain several limitations to defecography in general. Radiation exposure for barium studies makes this test unsuitable for certain patient groups, 
particularly pregnant women. As with all tests of evacuatory function, defecography is not performed in response to the spontaneous desire to defecate, and embarrassment in the patient can inhibit normal behaviour, leading to overdiagnosis of impaired evacuation ${ }^{173}$; nevertheless, the diagnostic yield of functional disorders on defecography is approximately half that using other tests of evacuatory function ${ }^{174}$. A paucity of normative data is available ${ }^{159}$, particularly for MR defecography ${ }^{165}$, and a large degree of overlap in results between patients and controls limits the interpretability of results ${ }^{159,161}$.

\section{Other technologies}

A number of further technologies designed to describe anorectal function exist, some of which are established but not in routine clinical use (for example, endoanal MRI)

\section{Table 2 | Clinical relevance of findings of investigations of anorectal physiological function}

\begin{tabular}{|c|c|c|c|}
\hline Function & Investigation & Finding & $\begin{array}{l}\text { Clinical } \\
\text { relevance }\end{array}$ \\
\hline \multicolumn{4}{|l|}{ Anus } \\
\hline \multirow[t]{5}{*}{ Motor } & \multirow[t]{3}{*}{ Anorectal manometry } & Anal hypotonia & +++ \\
\hline & & Anal hypertonia & ++ \\
\hline & & Anal hypocontractility & +++ \\
\hline & Electromyography & Reduced or abnormal myogenic activity & +++ \\
\hline & $\begin{array}{l}\text { Pudendal nerve terminal } \\
\text { motor latencies }\end{array}$ & Prolonged latency & + \\
\hline \multirow[t]{5}{*}{ Structure } & \multirow[t]{5}{*}{ Endoanal ultrasonography } & IAS defect & +++ \\
\hline & & IAS degeneration or atrophy & ++ \\
\hline & & IAS hypertrophy & ++ \\
\hline & & EAS atrophy & ++ \\
\hline & & EAS defect & +++ \\
\hline Sensory & Anal mucosal electrosensitivity & Anal hyposensitivity & ++ \\
\hline \multicolumn{4}{|l|}{ Rectum } \\
\hline \multirow[t]{2}{*}{ Sensory } & \multirow{2}{*}{$\begin{array}{l}\text { Balloon distension or rectal } \\
\text { barostat }\end{array}$} & Rectal hypersensitivity & +++ \\
\hline & & Rectal hyposensitivity & +++ \\
\hline \multirow{4}{*}{$\begin{array}{l}\text { Motor, } \\
\text { sensory } \\
\text { and } \\
\text { structure }\end{array}$} & \multirow[t]{4}{*}{ Rectal barostat } & Rectal hypercompliance & ++ \\
\hline & & Rectal hypocompliance & ++ \\
\hline & & Increased rectal capacity & ++ \\
\hline & & Decreased rectal capacity & ++ \\
\hline \multicolumn{4}{|c|}{ Anorectal unit } \\
\hline \multirow[t]{5}{*}{ Motor } & Balloon expulsion & Prolonged expulsion time & +++ \\
\hline & \multirow[t]{4}{*}{ Anorectal manometry } & Pelvic akinesia (can be described as type IV dyssynergia) & +++ \\
\hline & & $\begin{array}{l}\text { Poor propulsion with dyssynergia (can be described as } \\
\text { type ll dyssynergia) }\end{array}$ & ++ \\
\hline & & $\begin{array}{l}\text { Normal propulsion with dyssynergia (can be described as } \\
\text { type I or III dyssynergia) }\end{array}$ & ++ \\
\hline & & Anorectal areflexia & +++ \\
\hline \multirow{10}{*}{$\begin{array}{l}\text { Motor, } \\
\text { sensory } \\
\text { and } \\
\text { structure }\end{array}$} & \multirow[t]{10}{*}{ Defecography (barium or MRI) } & Obstructing intussusception & +++ \\
\hline & & Retaining rectocele & +++ \\
\hline & & Megarectum & + \\
\hline & & Rectal prolapse & +++ \\
\hline & & Enterocele or sigmoidocele & ++ \\
\hline & & Cystocele & ++ \\
\hline & & Vaginal vault prolapse & ++ \\
\hline & & Excessive perineal descent & ++ \\
\hline & & Impaired rectal emptying ${ }^{a}$ & +++ \\
\hline & & Impaired anorectal angle opening ${ }^{a}$ & ++ \\
\hline
\end{tabular}

+ , finding of questionable clinical importance; ++, finding of minor clinical importance; +++, finding of major clinical importance; EAS, external anal sphincter; IAS, internal anal sphincter. ${ }^{2}$ Functional (as opposed to structural) abnormality of evacuation. 
and others that are emerging (for example, the functional lumen imaging probe). Primarily acknowledged as tools in the research setting, they provide useful insights into the mechanisms of anorectal (dys)function. Although the following list is not exhaustive, it is a brief introduction to those modalities that the Consensus Group believes to have some diagnostic capability.

\section{Functional lumen imaging probe}

The anal canal's passive ability to withstand opening pressure (that is, distensibility) is thought to have a role in the continence mechanism ${ }^{175}$. A novel device, the functional lumen imaging probe (Flip; Crospon, Ireland) measures the cross-sectional diameter of a saline-filled balloon within the anal canal as distension pressure increases. Early studies show that patients with faecal incontinence have increased distensibility of the anal canal, and this finding can be more sensitive to clinically relevant pathology than $\mathrm{ARM}^{176,177}$.

\section{Rectal and anal motor-evoked potentials}

The integrity of spinoanorectal pathways that govern anorectal neuronal function can be assessed using magnetic stimulation of the lumbar and sacral regions overlying the nerve plexi and recording the motor evoked potentials ${ }^{178}$. More specifically, motor evoked potentials can reveal either unilateral or bilateral prolonged motorevoked potentials at the lumbar region and/or sacral region and at the rectal and/or anal sites ${ }^{179}$.

A study showed that translumbar and trans-sacral motor-evoked potentials of the rectum and anus provide better delineation of peripheral neuromuscular injury in individuals with faecal incontinence and spinal cord injury than PNTMLs ${ }^{180}$. This approach is relatively easy to perform, but it is not widely available, which is the major limitation.

\section{Endoanal MRI}

Endoanal MRI ${ }^{48,181,182}$ is a technique that enables highresolution imaging of the EAS (with the ability to differentiate between defects, scarring and atrophy) together with visualization of surrounding structures pertinent to pelvic organ prolapse and faecal incontinence (detecting, for example, pubovisceral avulsion). Additionally, MRI muscle fibre tracking is a research technique that has enabled detailed functional assessments of the anatomy of the continence mechanism, including morphology of the EAS and puborectalis complex ${ }^{181}$.

\section{Anorectal dysfunction \\ Physiological classification}

No single test can fully characterize the cause(s) of faecal incontinence and evacuation disorders; instead, a range of investigations should be applied to assess anorectal structure, function and sensitivity (TABLE 1). We also recognize that there is no widely accepted consensus on the physiological nomenclature for the classification of anorectal disorders or the use of findings from anorectal investigations to broadly describe phenotypes.

A broad summary of the expert consensus view regarding findings of each investigation discussed

\section{Box 2 | Open research questions}

- The optimal manometric measurements for diagnosis of sphincter dysfunction and rectoanal coordination need to be refined and better defined.

- The clinical importance of measurements and tools used to assess rectal capacity, compliance and sensory function in patients with anorectal disorders requires further validation in clinical practice.

- Classification systems for physiological characterization of faecal incontinence and evacuation disorders that integrate the results of ARM, anorectal sensation, anal endosonography and defecography are required.

- Serial diagnostic and outcome studies are needed to assess the clinical utility of anorectal investigations for stratifying patients to behavioural, medical or surgical therapies.

earlier is presented in TABLE 2, with the clinical relevance classified as 'major', 'minor' and 'of questionable significance'.

Faecal incontinence. In the context of faecal incontinence, major physiological findings with clear implications for clinical management and/or prognosis include anal hypotonia, anal hypocontractility and large sphincter defects on endoanal ultrasonography (TABLE 2). However, owing to the multifactorial nature of symptom generation, such abnormal physiological findings are rarely found alone and are often seen in overlapping clusters. Examples of well-recognized physiological phenotypes include anal hypotonia, IAS hypertrophy and rectoanal intussusception or full-thickness rectal prolapse in patients with symptoms of passive faecal leakage ${ }^{105,183,184}$ and anal hypocontractility, rectal hypersensitivity and rectal hypocompliance in patients with faecal urgency or incontinence or diarrhoea-predominant IBS ${ }^{124,185-187}$. However, although anecdotally recognized, prospective studies are required to better characterize these phenotypes, symptom clusters and disorders.

Evacuation disorders. For evacuation disorders, major findings include impaired emptying secondary to abnormal rectal structure (intussusception, prolapse or rectocele) or function (impaired propulsion or dyssynergia) and abnormalities of rectal sensitivity (in particular, rectal hyposensitivity). Again, recognized phenotypes are often characterized by more than one physiological abnormality (for example, rectal hyposensitivity with impaired evacuation secondary to enlarged rectal capacity, hypercompliance or megarectum ${ }^{130}$ ), and these also merit further study.

\section{Effect of physiological evaluation on management}

Epidemiological research has demonstrated that diarrhoea is the most important cause of faecal incontinence (OR 53, 95\% CI 6.1-147, compared with continent controls $)^{156}$ and hard stool is the most common finding in constipation ${ }^{188}$. However, symptoms of disordered defecation can be secondary to abnormalities outside the anorectum, such as colonic dysfunction ${ }^{189}$, or they 
can be due to obsessive-compulsive disorders and/or somatization ${ }^{190}$. Hence, physiological assessments should be considered for patients whose symptoms have not responded to stool regulation.

The clinical utility of physiological measurement has previously been confirmed in large case series ${ }^{24,191}$; however, high-quality data from prospective trials using contemporary technology with outcome data are limited. Study design is challenging owing to difficulties defining patient groups on the basis of (nonspecific) symptoms, the wide range of normal values and the variety of potential physiological findings.

The problem of overlap between health and disease is particularly pertinent in this field, as demonstrated in a blinded study of ARM in healthy individuals and patients with constipation in which $90 \%$ of healthy individuals were classified as 'abnormal' using conventional descriptors of rectoanal coordination ${ }^{70}$. Thus, test results should be interpreted with an appropriate degree of caution (particularly when planning irreversible surgical correction of a physiological or structural 'abnormality') until further robustly performed stratified medicine studies become available.

Furthermore, it should not be assumed that a single measurable physiological change directly correlates with a single symptom, as these diseases are often multifactorial. As has been demonstrated elsewhere, treatment directed at one physiological abnormality might yield poor results when the true pathological driver is not fully appreciated (for example, gastric acid suppression therapy for duodenal ulceration secondary to Helicobacter pylori infection) ${ }^{192}$.

However, the particular findings on physiological testing do currently act as a basis for clinical management (for example, anal hypocontractility with an EAS defect after obstetric injury), but there remains a need for further development of an evidence-based classification system of physiological phenotypes. This development will require serial diagnostic and outcome studies to assess the clinical utility of the system for the direction of specific behavioural, medical and surgical interventions.

\section{Conclusions}

If anorectal symptoms persist despite empirical stool regulation therapy without identification of a treatable cause, anorectal function testing can provide information that might explain the causes of faecal incontinence or evacuation disorders. This Consensus Statement has identified challenges concerning data acquisition, analysis and interpretation of results (BOX 2); however, there is a high level of agreement that the evaluation of anorectal structure and function and mechanistic understanding of anorectal pathophysiology can identify disease phenotypes and direct effective management.
1. Palit, S., Lunniss, P. J. \& Scott, S. M. The physiology of human defecation. Dig. Dis. Sci. 57, 1445-1464 (2012).

2. Perry, S. et al. Prevalence of faecal incontinence in adults aged 40 years or more living in the community. Gut 50, 480-484 (2002).

3. Whitehead, W. E. et al. Fecal incontinence in US adults: epidemiology and risk factors. Gastroenterology 137, 512-517 (2009).

4. Johanson, J. F. \& Lafferty, J. Epidemiology of fecal incontinence: the silent affliction.

Am. J. Gastroenterol. 91, 33-36 (1996).

5. Higgins, P. D. \& Johanson, J. F. Epidemiology of constipation in North America: a systematic review. Am. J. Gastroenterol. 99, 750-759 (2004).

6. Noelting, J. et al. The incidence rate and characteristics of clinically diagnosed defecatory disorders in the community. Neurogastroenterol. Motil. 28, 1690-1697 (2016)

7. Scott, S. M. \& Gladman, M. A. Manometric, sensorimotor, and neurophysiologic evaluation of anorectal function. Gastroenterol. Clin. North Am. 37 511-538 (2008)

8. Norton, C. et al. Management of faecal incontinence in adults: summary of NICE guidance. BMJ 334, 13701371 (2007).

9. Keighley, M. R. B. in Surgery of the Anus, Rectum Colon Vol. 1 (ed. Keighley, M. R. B.) 516-608 (Saunders, London, 1993).

10. Bharucha, A. E. et al. American Gastroenterological Association medical position statement on constipation. Gastroenterology 144, 211-217 (2013).

11. Bharucha, A. E. Fecal incontinence. Gastroenterology 124, 1672-1685 (2003)

12. Quander, C. R. et al. Prevalence of and factors associated with fecal incontinence in a large community study of older individuals. Am. J. Gastroenterol. 100, 905-909 (2005).

13. Alimohammadian, M. et al. Suffering in silence: a community-based study of fecal incontinence in women. Int. J. Colorectal Dis. 29, 401-406 (2014).

14. Fynes, M. et al. Effect of second vaginal delivery on anorectal physiology and faecal continence: a prospective study. Lancet 354, 983-986 (1999).

15. Rao, S. S. Pathophysiology of adult fecal incontinence. Gastroenterology 126, S14-22 (2004).
16. Damon, $\mathrm{H}$. et al. Prevalence of anal incontinence in adults and impact on quality-of-life Gastroenterol. Clin. Biol. 30, 37-43 (2006).

17. Kamm, M. A. Obstetric damage and faecal incontinence. Lancet 344, 730-733 (1994).

18. Goldberg, R. P. et al. Delivery mode is a majo environmental determinant of stress urinary incontinence: results of the Evanston-Northwestern Twin Sisters Study. Am. J. Obstet. Gynecol. 193 2149-2153 (2005).

19. Lunniss, P. J. et al. Risk factors in acquired faecal incontinence. J. R. Soc. Med. 97, 111-116 (2004).

20. Kim, T. et al. Faecal incontinence in male patients. Colorectal Dis. 10, 124-130 (2008)

21. Nurko, S. \& Scott, S. M. Coexistence of constipation and incontinence in children and adults. Best Pract. Res. Clin. Gastroenterol. 25, 29-41 (2011).

22. Tantiphlachiva, K. et al. Digital rectal examination is a useful tool for identifying patients with dyssynergia. Clin. Gastroenterol. Hepatol. 8, 955-960 (2010).

23. Lam, T. \& Felt-Bersma, R. Clinical examination remains more important than anorectal function tests to identify treatable conditions in women with constipation. Int. Urogynecol. J. 24, 67-72 (2013).

24. Vaizey, C. J. \& Kamm, M. A. Prospective assessment of the clinical value of anorectal investigations. Digestion 61, 207-214 (2000).

25. Liberman, H. et al. A prospective evaluation of the value of anorectal physiology in the management of fecal incontinence. Dis. Colon Rectum 44, 15671574 (2001)

26. Altomare, D. F. et al. Reliability of electrophysiologic anal tests in predicting the outcome of sacral nerve modulation for fecal incontinence. Dis. Colon Rectum 47, 853-857 (2004).

27. Knowles, C. H. et al. Prospective randomized doubleblind study of temporary sacral nerve stimulation in patients with rectal evacuatory dysfunction and rectal hyposensitivity. Ann. Surg. 255, 643-649 (2012)

28. Chiarioni, G. et al. Sensory retraining is key to biofeedback therapy for formed stool fecal incontinence. Am. J. Gastroenterol. 97, 109-117 (2002).

29. Rao, S. S. et al. Minimum standards of anorectal manometry. Neurogastroenterol. Motil. 14, 553-559 (2002).

30. Azpiroz, F., Enck, P. \& Whitehead, W. E. Anorectal functional testing: review of collective experience. Am. J. Gastroenterol. 97, 232-240 (2002).
31. Diamant, N. E. et al. AGA technical review on anorectal testing techniques. Gastroenterology 116 , 735-760 (1999)

32. Carrington, E. V. et al. Methods of anorectal manometry vary widely in clinical practice: results from an international survey. Neurogastroenterol. Motil. 29, e13016 (2017)

33. Rao, S. S. \& Patel, R. S. How useful are manometric tests of anorectal function in the management of defecation disorders? Am. J. Gastroenterol. 92, 469-475 (1997)

34. Dinning, P., Carrington, E. \& Scott, S. M. Colonic and anorectal motility testing in the high-resolution era. Curr. Opin. Gastroenterol. 32, 44-48 (2016).

35. Dinning, P. G., Carrington, E. V. \& Scott, S. M. The use of colonic and anorectal high-resolution manometry and its place in clinical work and in research. Neurogastroenterol Motil. 27, 1693-1708 (2015).

36. Noelting, J. et al. Normal values for high-resolution anorectal manometry in healthy women: effects of age and significance of rectoanal gradient. Am. J. Gastroenterol. 107, 1530-1536 (2012).

37. Carrington, E. V. et al. Traditional measures of normal anal sphincter function using high-resolution anorectal manometry (HRAM) in 115 healthy volunteers. Neurogastroenterol Motil. 26, 625-635 (2014).

38. Sauter, M. et al. Toward more accurate measurements of anorectal motor and sensory function in routine clinical practice: validation of high-resolution anorectal manometry and Rapid Barostat Bag measurements of rectal function. Neurogastroenterol Motil. 26 685-695 (2014)

39. Li, Y. et al. Normal values and pressure morphology for three-dimensional high-resolution anorectal manometry of asymptomatic adults: a study in 110 subjects. Int. J. Colorectal Dis. 28, 1161-1168 (2013).

40. Coss-Adame, E. et al. Accuracy and reproducibility of high-definition anorectal manometry and pressure topography analyses in healthy subjects. Clin. Gastroenterol. Hepatol. 13, 1143-1150.e1 (2015)

41. Mion, F. et al. 3D High-definition anorectal manometry: values obtained in asymptomatic volunteers, fecal incontinence and chronic constipation. Results of a prospective multicenter study (NOMAD). Neurogastroenterol. Motil. 29 e13049 (2017). 
42. Banasiuk, M. et al. Values from three-dimensional high-resolution anorectal manometry analysis of children without lower gastrointestinal symptoms. Clin. Gastroenterol. Hepatol. 14, 993-1000.e3 (2016).

43. Wickramasinghe, D. P. et al. Three-dimensional anorectal manometry findings in primigravida. Dig. Dis. Sci. 60, 3764-3770 (2015).

44. Lestar, B., Penninckx, F. \& Kerremans, R. The composition of anal basal pressure. An in vivo and in vitro study in man. Int. J. Colorectal Dis. $\mathbf{4}$ 118-122 (1989).

45. Engel, A. F. et al. Relationship of symptoms in faecal incontinence to specific sphincter abnormalities. Int. J. Colorectal Dis. 10, 152-155 (1995).

46. Vaizey, C. J., Kamm, M. A. \& Bartram, C. I. Primary degeneration of the internal anal sphincter as a cause of passive faecal incontinence. Lancet 349, 612-615 (1997).

47. Felt-Bersma, R. J., Klinkenberg-Knol, E. C \& Meuwissen, S. G. Anorectal function investigations in incontinent and continent patients. Differences and discriminatory value. Dis. Colon Rectum 33, 479-485 (1990).

48. Bharucha, A. E. et al. Relationship between symptoms and disordered continence mechanisms in women with idiopathic faecal incontinence. Gut 54, 546-555 (2005).

49. Prichard, D. et al. Relationship among anal sphincter injury, patulous anal canal, and anal pressures in patients with anorectal disorders. Clin. Gastroenterol. Hepatol. 13, 1793-1800.e1 (2015).

50. Farouk, R. et al. Sustained internal sphincter hypertonia in patients with chronic anal fissure. Dis. Colon Rectum 37, 424-429 (1994).

51. Xynos, E. et al. Anal manometry in patients with fissure-in-ano before and after internal sphincterotomy. Int. J. Colorectal Dis. 8, 125-128 (1993).

52. Jones, O. M. et al. Digital rectal examination of sphincter pressures in chronic anal fissure is unreliable. Dis. Colon Rectum 48, 349-352 (2005).

53. Staller, K. et al. Resting anal pressure, not outlet obstruction or transit, predicts healthcare utilization in chronic constipation: a retrospective cohort analysis. Neurogastroenterol. Motil. 27, 1378-1388 (2015).

54. Telford, K. et al. Fatigability of the external anal sphincter in anal incontinence. Dis. Colon Rectum 47, 746-752 (2004)

55. Rao, S. S., Welcher, K. D. \& Leistikow, J. S. Obstructive defecation: a failure of rectoanal coordination. Am. J. Gastroenterol. 93, 1042-1050 (1998).

56. Bharucha, A. E. et al. Phenotypic variation in functional disorders of defecation. Gastroenterology 128, 1199-1210 (2005)

57. Carrington, E. V. et al. 'Pelvic floor akinesia' - a highly specific manometric finding in patients with defecatory dysfunction [abstract]. Gastroenterology 152 (Suppl. 1), 43 (2017)

58. Aaronson, I. \& Nixon, H. H. A clinical evaluation of anorectal pressure studies in the diagnosis of Hirschsprung's disease. Gut 13, 138-146 (1972).

59. Sangwan, Y. P. et al. Spectrum of abnormal rectoanal reflex patterns in patients with fecal incontinence. Dis. Colon Rectum 39, 59-65 (1996)

60. Xu, X. et al. Clinical significance of quantitative assessment of rectoanal inhibitory reflex (RAIR) in patients with constipation. J. Clin. Gastroenterol. 42 , 692-698 (2008)

61. Zbar, A. P. et al. Fecal incontinence after minor anorectal surgery. Dis. Colon Rectum 44, 1610-1623 (2001).

62. Rezaie, A. et al. Can 3D high resolution anorectal manometry detect anal sphincter defects in patients with faecal incontinence? Colorectal Dis. 19, 468475 (2016).

63. Vitton, V. et al. Comparison of three-dimensional highresolution manometry and endoanal ultrasound in the diagnosis of anal sphincter defects. Colorectal Dis. 15 e607-611 (2013).

64. Benezech, A. et al. Three-dimensional high-resolution anorectal manometry and diagnosis of excessive perineal descent: a comparative pilot study with defaecography. Colorectal Dis. 16, 0170-175 (2014).

65. Benezech, A. et al. Rectal intussusception: can high resolution three-dimensional ano-rectal manometry compete with conventional defecography? Neurogastroenterol. Motil. https://doi.org/10.1111 nmo.12978 (2016).

66. Heinrich, H. et al. Assessment of obstructive defecation by high-resolution anorectal manometry compared with magnetic resonance defecography. Clin. Gastroenterol. Hepatol. 13, 1310-1317.e1 (2015).

67. Sun, W. M., Donnelly, T. C. \& Read, N. W. Utility of a combined test of anorectal manometry, electromyography, and sensation in determining the mechanism of 'idiopathic' faecal incontinence. Gut 33, 807-813 (1992).

68. Maeda, Y. et al. Physiological, psychological and behavioural characteristics of men and women with faecal incontinence. Colorectal Dis. 11, 927-932 (2009).

69. Zbar, A. P. et al. Use of vector volume manometry and endoanal magnetic resonance imaging in the adult female for assessment of anal sphincter dysfunction. Dis. Colon Rectum 42, 1411-1418 (1999)

70. Grossi, U. et al. Diagnostic accuracy study of anorectal manometry for diagnosis of dyssynergic defecation. Gut 65, 447-455 (2016).

71. Jones, M. P., Post, J. \& Crowell, M. D. High-resolution manometry in the evaluation of anorectal disorders: a simultaneous comparison with water-perfused manometry. Am. J. Gastroenterol. 102, 850-855 (2007).

72. Fang, J. C. et al. Comparison of air-coupled balloon esophageal and anorectal manometry catheters with solid-state esophageal manometry and water-perfused anorectal manometry catheters. Dig. Dis. Sci. 49, 1657-1663 (2004).

73. Simpson, R. R. et al. Anal manometry: a comparison of techniques. Dis. Colon Rectum 49, 1033-1038 (2006)

74. Vitton, V. et al. Water-perfused manometry versus 3D high resolution manometry: a comparative study on a large patient population with ano-rectal disorders. Colorectal Dis. 15, e726-e731 (2013).

75. Kang, H. R. et al. Comparison of high-resolution anorectal manometry with water-perfused anorectal manometry. J. Neurogastroenterol. Motil. 21, 126-132 (2015).

76. Thekkinkattil, D. K. et al. Contribution of posture to anorectal manometric measurements: are the measurements in left-lateral position physiologic? Dis. Colon Rectum 50, 2112-2119 (2007).

77. Snooks, S. et al. Effect of vaginal delivery on the pelvic floor: a 5-year follow-up. Br. J. Surg. 77, 1358-1360 (1990)

78. Parks, A., Swash, M. \& Urich, H. Sphincter denervation in anorectal incontinence and rectal prolapse. Gut 18, 656-665 (1977).

79. Lefaucheur, J. P. Neurophysiological testing in anorectal disorders. Muscle Nerve 33, 324-333 (2006)

80. Rogers, J., Henry, M. \& Misiewicz, J. Disposable pudendal nerve stimulator: evaluation of the standard instrument and new device. Gut 29, 1131-1133 (1988)

81. Thomas, C. et al. Respective value of pudendal nerve terminal motor latency and anal sphincter electromyography in neurogenic fecal incontinence. Neurophysiol. Clin. 32, 85-90 (2002).

82. Gregory, W. T. et al. Quantitative electromyography of the anal sphincter after uncomplicated vaginal delivery. Obstet Gynecol. 104, 327-335 (2004).

83. Wexner, S. D. et al. Neurophysiologic assessment of the anal sphincters. Dis. Colon Rectum 34, 606-612 (1991).

84. Olsen, A. L. \& Rao, S. S. Clinical neurophysiology and electrodiagnostic testing of the pelvic floor. Gastroenterol. Clin. North Amer. 30, 33-54 (2001).

85. Sørensen, M. et al. Relation between electromyography and anal manometry of the external anal sphincter. Gut 32, 1031-1034 (1991).

86. Merletti, R. et al. Multichannel surface EMG for the non-invasive assessment of the anal sphincter muscle. Digestion 69, 112-122 (2004)

87. Wexner, S. D. et al. Prospective assessment of biofeedback for the treatment of paradoxical puborectalis contraction. Dis. Colon Rectum 35 145-150 (1992)

88. Heymen, S. et al. Biofeedback treatment of fecal incontinence. Dis. Colon Rectum 44, 728-736 (2001)

89. Enck, P., Van der Voort, I. \& Klosterhalfen, S. Biofeedback therapy in fecal incontinence and constipation. Neurogastroenterol. Motil. 21, 1133-1141 (2009).

90. Cheong, D. M. et al. Electrodiagnostic evaluation of fecal incontinence. Muscle Nerve 18, 612-619 (1995).
91. Lacima, G. et al. Is electromyography a predictive test of patient response to biofeedback in the treatment of fecal incontinence? Neurourol. Urodynam. 35, 390394 (2016).

92. Abdool, Z., Sultan, A. H. \& Thakar, R. Ultrasound imaging of the anal sphincter complex: a review. Br. J. Radiol. 85, 865-875 (2012).

93. Hainsworth, A. J. et al. Integrated total pelvic floor ultrasound in pelvic floor defaecatory dysfunction. Colorectal Dis. 19, 054-065 (2017).

94. Stoker, J. et al. Imaging of anorectal disease. Br. J. Surg. 87, 10-27 (2000).

95. Karmarkar, R. et al. Mode of delivery after obstetric anal sphincter injury. Eur. J. Obstet. Gynecol. Reprod. Biol. 194, 7-10 (2015).

96. Harvey, M.-A. et al. Obstetrical anal sphincter injuries (oasis): prevention, recognition, and repair. J. Obstet. Gynaecol. Canada 37, 1131-1148 (2015).

97. Bipat, S. et al. Rectal cancer: local staging and assessment of lymph node involvement with endoluminal US, CT, and MR imaging - a metaanalysis. Radiology 232, 773-783 (2004).

98. Oom, D. M. et al. Detection of anal sphincter defects in female patients with fecal incontinence: a comparison of 3-dimensional transperineal ultrasound and 2-dimensional endoanal ultrasound. Dis. Colon Rectum 55, 646-652 (2012).

99. Williams, A. B. et al. Anal sphincter damage after vaginal delivery using three-dimensional endosonography. Obstet. Gynecol. 97, 770-775 (2001).

100. Albuquerque, A. \& Pereira, E. Current applications of transperineal ultrasound in gastroenterology. World J. Radiol. 8, 370 (2016)

101. Steensma, A. B. in Atlas of Pelvic Floor Ultrasound (eds Dietz, H. P., Hoyte, L. P. \& Steensma, A. B.) 63-75 (Springer, London, 2008).

102. Beets-Tan, R. G. et al. Measurement of anal sphincter muscles: endoanal US, endoanal MR imaging, or phased-array MR imaging? A study with healthy volunteers. Radiology 220, 81-89 (2001).

103. Albuquerque, A. $\&$ Macedo, G. Idiopathic internal ana sphincter degeneration: how common is it? Does size really matter? Colorectal Dis. 19, 396-397 (2017).

104. Halligan, S. et al. Endosonography of the anal sphincters in solitary rectal ulcer syndrome. Int. J. Colorectal Dis. 10, 79-82 (1995).

105. Dvorkin, L. S. et al. Anal sphincter morphology in patients with full-thickness rectal prolapse. Dis. Colon Rectum 47, 198-203 (2004).

106. Marshall, M. et al. Predictive value of internal anal sphincter thickness for diagnosis of rectal intussusception in patients with solitary rectal ulcer syndrome. Br. J. Surg. 89, 1281-1285 (2002).

107. Sultan, A. H. et al. Anal-sphincter disruption during vaginal delivery. N. Engl. J. Med. 329, 1905-1911 (1993).

108. Mahony, R. et al. Internal anal sphincter defect influences continence outcome following obstetric anal sphincter injury. Am. J Obstet. Gynecol. 196, 217. e1-217. e5 (2007)

109. Titi, M. et al. Correlation between anal manometry and endosonography in females with faecal incontinence. Colorectal Dis. 10, 131-137 (2008).

110. Pinsk, I., Brown, J. \& Phang, P. Assessment of sonographic quality of anal sphincter muscles in patients with faecal incontinence. Colorectal Dis. 11 933-940 (2009)

111. Townsend, D. et al. Pathophysiology of fecal incontinence differs between men and women: a casematched study in 200 patients. Neurogastroenterol. Motil. 28, 1580-1588 (2016)

112. Valsky, D. V. et al. Third-or fourth[degree intrapartum anal sphincter tears are associated with levator ani avulsion in primiparas. J. Ultrasound Med. 35, 709715 (2016).

113. Shek, K., Guzman-Rojas, R. \& Dietz, H. Residual defects of the external anal sphincter following primary repair: an observational study using transperineal ultrasound Ultrasound Obstet. Gynecol. 44, 704-709 (2014).

114. Bharucha, A. E. et al. Obstetric trauma, pelvic floor injury and fecal incontinence: a population-based casecontrol study. Am. J. Gastroenterol. 107, 902-911 (2012).

115. Bharucha, A. E. Update of tests of colon and rectal structure and function. J. Clin. Gastroenterol. 40, 96-103 (2006).

116. Gladman, M. A. et al. Rectal hyposensitivity: a disorder of the rectal wall or the afferent pathway? An assessment using the barostat. Am. J. Gastroenterol. 100, 106-114 (2005) 
117. Whitehead, W. E. \& Delvaux, M. Standardization of barostat procedures for testing smooth muscle tone $\&$ sensory thresholds in the gastrointestinal tract. Dig. Dis. Sci. 42, 223-241 (1997).

118. Fox, M. et al. Determinants of fecal continence in healthy, continent subjects: a comprehensive analysis by anal manometry, rectal barostat and a stool substitute retention test. Digestion 83, 46-53 (2011)

119. Cremonini, F. et al. Barostat testing of rectal sensation and compliance in humans: comparison of results across two centres and overall reproducibility. Neurogastroenterol. Motil. 17, 810-820 (2005)

120. Gladman, M. A. et al. Rectal hyposensitivity. Am. J. Gastroenterol. 101, 1140-1151 (2006).

121. Simren, M. et al. Visceral hypersensitivity is associated with $\mathrm{Gl}$ symptom severity in functional Gl disorders: consistent findings from five different patient cohorts. Gut 67, 255-262 (2018).

122. Chan, C. L. et al. Rectal hypersensitivity worsens stool frequency, urgency, and lifestyle in patients with urge fecal incontinence. Dis. Colon Rectum 48, 134-140 (2005).

123. Rao, G. N. et al. Anterior resection syndrome is secondary to sympathetic denervation. Int. J. Colorectal Dis. 11, 250-258 (1996).

124. Chan, C. L. et al. Rectal sensorimotor dysfunction in patients with urge faecal incontinence: evidence from prolonged manometric studies. Gut 54, 1263-1272 (2005).

125. Houghton, L. A. et al. Visceral sensation and emotion: a study using hypnosis. Gut 51, 701-704 (2002)

126. Houghton, L. A. et al. Effect of a second-generation a $2 \delta$ ligand (pregabalin) on visceral sensation in hypersensitive patients with irritable bowel syndrome. Gut 56, 1218-1225 (2007)

127. Algladi, T. et al. Modulation of human visceral sensitivity by noninvasive magnetoelectrical neural stimulation in health and irritable bowel syndrome. Pain 156, 1348-1356 (2015)

128. Harraf, F. et al. Subtypes of constipation predominant irritable bowel syndrome based on rectal perception. Gut 43, 388-394 (1998).

129. Burgell, R. E. \& Scott, S. M. Rectal hyposensitivity. J. Neurogastroenterol. Motil. 18, 373-384 (2012).

130. Gladman, M. A et al. Rectal hyposensitivity: pathophysiological mechanisms. Neurogastroenterol. Motil. 21, 508-516 (2009)

131. Sun, W. M., Read, N. W. \& Miner, P. B. Relation between rectal sensation and anal function in normal subjects and patients with faecal incontinence. Gut 31 1056-1061 (1990)

132. Wald, A. \& Tunuguntla, A. K. Anorectal sensorimotor dysfunction in fecal incontinence and diabetes mellitus. Modification with biofeedback therapy. N. Engl. J. Med. 310, 1282-1287 (1984)

133. Buser, W. D., Miner, P. B. Jr. Delayed rectal sensation with fecal incontinence. Successful treatment using anorectal manometry. Gastroenterology 91, 11861191 (1986)

134. Rhee, P.-L. et al. An increased rectal maximum tolerable volume and long anal canal are associated with poor short-term response to biofeedback therapy for patients with anismus with decreased bowel frequency and normal colonic transit time. Dis. Colon Rectum 43, 1405-1411 (2000).

135. Knowles, C. H., Scott, M. \& Lunniss, P. J. Outcome of colectomy for slow transit constipation. Ann. Surg. 230, 627-638 (1999).

136. Chiarioni, G. et al. Biofeedback is superior to laxatives for normal transit constipation due to pelvic floor dyssynergia. Gastroenterology 130, 657-664 (2006).

137. Rao, S. S., Welcher, K. D. \& Pelsang, R. E. Effects of biofeedback therapy on anorectal function in obstructive defecation. Dig. Dis. Sci. 42, 2197-2205 (1997).

138. Lindberg, G. et al. World Gastroenterology Organisation global guideline: constipation - a global perspective. J. Clin. Gastroenterol. 45, 483-487 (2011).

139. Wald, A. et al. ACG clinical guideline: management of benign anorectal disorders. Am. J. Gastroenterol. 109, 1141-1157 (2014)

140. Sun, W. M. et al. Sensory and motor responses to rectal distention vary according to rate and pattern of balloon inflation. Gastroenterology 99, 1008-1015 (1990).

141. Fox, J. C. et al. Effect of aging on anorectal and pelvic floor functions in females. Dis. Colon Rectum $\mathbf{4 9}$ 1726-1735 (2006).

142. Chiarioni, G. et al. Validation of the balloon evacuation test: reproducibility and agreement with findings from anorectal manometry and electromyography. Clin. Gastroenterol. Hepatol. 12, 2049-2054 (2014).

143. Minguez, M. et al. Predictive value of the balloon expulsion test for excluding the diagnosis of pelvic floor dyssynergia in constipation. Gastroenterology 126, 57-62 (2004)

144. Rao, S. S., Ozturk, R. \& Laine, L. Clinical utility of diagnostic tests for constipation in adults: a systematic review. Am. J. Gastroenterol. 100, 1605-1615 (2005)

145. Palit, S. et al. Diagnostic disagreement between tests of evacuatory function: a prospective study of 100 constipated patients. Neurogastroenterol. Motil. 28 1589-1598 (2016)

146. Chiarioni, G., Salandini, L. \& Whitehead, W. E. Biofeedback benefits only patients with outlet dysfunction, not patients with isolated slow transit constipation. Gastroenterology 129, 86-97 (2005).

147. Rao, S. S. et al. Randomized controlled trial of biofeedback, sham feedback, and standard therapy for dyssynergic defecation. Clin. Gastroenterol. Hepatol. 5, 331-338 (2007).

148. Shim, L. et al. Predictors of outcome of anorectal biofeedback therapy in patients with constipation Aliment. Pharmacol. Ther. 33, 1245-1251 (2011).

149. Lee, J. et al. Balloon expulsion test does not seem to be useful for screening or exclusion of dyssynergic defecation as a single test. J. Neurogastroenterol. Motil. 23, 446-452 (2017).

150. Dedeli, O. et al. Normative values of the balloon expulsion test in healthy adults. Turk. J. Gastroenterol. 18, 177-181 (2007).

151. Mahieu, P., Pringot, J. \& Bodart, P. Defecography: I. Description of a new procedure and results in norma patients. Gastrointest. Radiol. 9, 247-251 (1984).

152. Lunniss, P. J. et al. Pathophysiology of evacuation disorders. Neurogastroenterol. Motil. 21 (Suppl. 2), 31-40 (2009).

153. Roos, J. E. et al. Experience of 4 years with open MR defecography: pictorial review of anorectal anatomy and disease. Radiographics 22, 817-832 (2002).

154. Mortele, K. J. \& Fairhurst, J. Dynamic MR defecography of the posterior compartment: Indications, techniques and MRI features. Eur. J. Radiol 61, 462-472 (2007)

155. Fletcher, J. G. et al. Magnetic resonance imaging of anatomic and dynamic defects of the pelvic floor in defecatory disorders. Am. J. Gastroenterol. 98, 399-411 (2003).

156. Bharucha, A. E. et al. Bowel disturbances are the most important risk factors for late onset fecal incontinence: a population-based case-control study in women. Gastroenterology 139, 1559-1566 (2010).

157. Van Dam, J. et al. Role of defecography in predicting clinical outcome of rectocele repair. Dis. Colon Rectum 40, 201-207 (1997).

158. Hübner, M. et al. A prospective comparison between clinical outcome and open-configuration magnetic resonance defecography findings before and after surgery for symptomatic rectocele. Colorectal Dis. 8, 605-611 (2006).

159. Palit, S. et al. Evacuation proctography: a reappraisa of normal variability. Colorectal Dis. 16, 538-546 (2014).

160. Chan, C. L. et al. Exaggerated rectal adaptation another cause of outlet obstruction. Colorectal Dis. 3 141-142 (2001).

161. Shorvon, P. et al. Defecography in normal volunteers: results and implications. Gut 30, 1737-1749 (1989)

162. Collinson, R. et al. Rectal intussusception and unexplained faecal incontinence: findings of a proctographic study. Colorectal Dis. 11, 77-83 (2009).

163. Morandi, C. et al. Role of enterocele in the obstructed defecation syndrome (ODS): a new radiological point of view. Colorectal Dis. 12, 810-816 (2010).

164. Piloni, V., Tosi, P. \& Vernelli, M. MR-defecography in obstructed defecation syndrome (ODS): technique, diagnostic criteria and grading. Techniques Coloproctol. 17, 501-510 (2013).

165. Goh, V. et al. Dynamic MR imaging of the pelvic floor in asymptomatic subjects. AJR Am. J. Roentgenol 174, 661-666 (2000)

166. Pilkington, S. et al. Barium proctography versus magnetic resonance proctography for pelvic floo disorders: a comparative study. Colorectal Dis. 14 $1224-1230$ (2012)

167. Dvorkin, L. S. et al. Open-magnet MR defaecography compared with evacuation proctography in the diagnosis and management of patients with rectal intussusception. Colorectal Dis. 6, 45-53 (2004).

168. van lersel, J. et al. Comparison of dynamic magnetic resonance defaecography with rectal contrast and conventional defaecography for posterior pelvic floor compartment prolapse. Colorectal Dis. 19, O46-O53 (2017).

169. Zafar, A. et al. Comparative study of magnetic resonance defaecography and evacuation proctography in the evaluation of obstructed defaecation. Colorectal Dis. 19, O204-O209 (2017).

170. Bertschinger, K. M. et al. Dynamic MR imaging of the pelvic floor performed with patient sitting in an openmagnet unit versus with patient supine in a closedmagnet unit 1. Radiology 223, 501-508 (2002)

171. Schouten, W. et al. Anismus: fact or fiction? Dis. Colon Rectum 40, 1033-1041 (1997).

172. Bove, A. et al. Consensus statement AIGO/SICCR: diagnosis and treatment of chronic constipation and obstructed defecation (part I: diagnosis). World J. Gastroenterol. 18, 1555-1564 (2012).

173. Duthie, G. \& Bartolo, D. Anismus: the cause of constipation? Results of investigation and treatment. World J. Surg. 16, 831-835 (1992).

174. Videlock, E., Lembo, A. \& Cremonini, F. Diagnostic testing for dyssynergic defecation in chronic constipation: meta-analysis. Neurogastroenterol. Motil. 25, 509-e370 (2013).

175. Luft, F. et al. Functional luminal imaging probe: a new technique for dynamic evaluation of mechanical properties of the anal canal. Techniques Coloproctol. 16, 451-457 (2012)

176. Sorensen, G. et al. Distensibility of the anal canal in patients with idiopathic fecal incontinence: a study with the Functional Lumen Imaging Probe. Neurogastroenterol. Motil. 26, 255-263 (2014).

177. Gourcerol, G. et al. Do endoflip assessments of anal sphincter distensibility provide more information on patients with fecal incontinence than high-resolution anal manometry? Neurogastroenterol. Motil. $\mathbf{2 8}$ 399-409 (2016).

178. Remes-Troche, J. M. et al. A bi-directional assessment of the human brain-anorectal axis. Neurogastroenterol. Motil. 23, 240-248 (2011).

179. Paris, G. et al. Evoked pressure curves from the external anal sphincter following transcranial magnetic stimulation in healthy volunteers and patients with faecal incontinence. Colorectal Dis. 15, e732-e740 (2013).

180. Tantiphlachiva, K. et al. Translumbar and transsacral motor-evoked potentials: a novel test for spinoanorectal neuropathy in spinal cord injury. Am. J. Gastroenterol. 106, 907-914 (2011)

181. Mittal, R. K. et al. Purse-string morphology of external anal sphincter revealed by novel imaging techniques. Am. J. Physiol. Gastrointest. Liver Physiol. 306 G505-G514 (2014).

182. Heilbrun, M. E. et al. Correlation between levator ani muscle injuries on magnetic resonance imaging and fecal incontinence, pelvic organ prolapse, and urinary incontinence in primiparous women. Am. J. Obstet. Gynecol. 202, 499.e1-e6 (2010).

183. Harmston, C. et al. The relationship between internal rectal prolapse and internal anal sphincter function. Colorectal Dis. 13, 791-795 (2011).

184. Damon, H. et al. Influence of rectal prolapse on the asymmetry of the anal sphincter in patients with ana incontinence. BMC Gastroenterol. 3, 23 (2003).

185. Prior, A., Maxton, D. \& Whorwell, P. Anorectal manometry in irritable bowel syndrome: differences between diarrhoea and constipation predominant subjects. Gut 31, 458-462 (1990).

186. Salvioli, B. et al. Rectal compliance, capacity, and rectoanal sensation in fecal incontinence. $A m$. J. Gastroenterol. 96, 2158-2168 (2001).

187. Basilisco, G. et al. Bowel urgency in patients with irritable bowel syndrome. Gastroenterology 132 38-44 (2007).

188. Johanson, J. F., Sonnenberg, A. \& Koch, T. R. Clinical epidemiology of chronic constipation. J. Clin. Gastroenterol. 11, 525-536 (1989).

189. Dinning, P. G., Smith, T. K. \& Scott, S. M. Pathophysiology of colonic causes of chronic constipation. Neurogastroenterol. Motil. 21 (Suppl. 2), 20-30 (2009).

190. Rao, S. S. et al. Psychological profiles and quality of life differ between patients with dyssynergia and those with slow transit constipation. J. Psychosom. Res. 63, 441-449 (2007)

191. Halverson, A. L. ¿ Orkin, B. A. Which physiologic tests are useful in patients with constipation? Dis. Colon Rectum 41, 735-739 (1998).

192. Kusters, J. G., van Vliet, A. H. \& Kuipers, E. J. Pathogenesis of Helicobacter pylori infection. Clin. Microbiol. Rev. 19, 449-490 (2006). 


\section{Acknowledgements}

The International Working Group for Disorders of Gastrointestinal Motility and Function initiated the consensus meetings and provided material support for the consensus process. Five separate groups reviewed the current state-of-the-art in clinical measurement of gastrointestinal motility and function: oropharynx, oesophagus, reflux disease, stomach/intestine and anorectum. This process was endorsed by the European Society of Neurogastroenterology and Motility (ESNM), and the European Society of Colo-Proctology (ESCP) with representation and support from members of the American Neurogastroenterology and Motility Society (ANMS), the South American and Latin Society (SLNG), the Asian Neurogastroenterology and Motility Association (ANMA) and the Australasian Neurogastroenterology and Motility Association (ANGMA). Financial support was provided by the United European Gastroenterology (UEG) Education Committee, registration fees for meetings and sponsorship from major manufacturers of physiological measurement equipment.

AB is supported by USPHS NIH Grant DKDK78924.

\section{Author contributions}

All authors made equal contributions to all aspects of this manuscript.

\section{Competing interests}

E V.C. has received honoraria for teaching from Medical Measurement Systems/Laborie. S.M.S. has received honoraria for teaching from Medical Measurement Systems Laborie. A.B. has licensed intellectual property in a portable anorectal manometry device to Medspira. F.M. has served as consultant for Medtronic and Medical Measurement Systems/ Laborie. J.M.R.-T. has received research funding from Newton Foundation-CONACYT, Sanfer and Asofarma Laboratories and speaker fees from Covidien/Medtronics, Takeda, Allergan, AstraZeneca, Sanofi and Sanfer. M.F. has received research funding from Covidien/Medtronic and speaker fees from Covidien/Medtronic, Sandhill, Medical Measurement Systems/ Laborie, Reckitt Benckiser and Mui Scientific. S.S.R. has served on advisory boards for Forest Laboratories, Synergy Pharmaceuticals, Vibrant and InTone and has received research grants from Forest Laboratories, Synergy, InTone and Medtronic. H.H. and A.M. declare no competing interests.
Publisher's note

Springer Nature remains neutral with regard to jurisdictional claims in published maps and institutional affiliations.

This work is licensed under a Creative Commons Attribution 4.0 International License. The images or other third party material in this article are included in the article's Creative Commons license, unless indicated otherwise in the credit line; if the material is not included under the Creative Commons license, users will need to obtain permission from the license holder to reproduce the material. To view a copy of this license, visit http://creativecommons.org/ licenses/by/4.0/.

\section{RELATED LINKS}

International Working Group for Disorders of Gastrointestinal

Motility and Function: https://www.idigest.ch/

ALL LINKS ARE ACTIVE IN THE ONLINE PDF 